\title{
Community dynamics under environmental change: How can next generation mechanistic models improve projections of species distributions?
}

\author{
Alexander Singer ${ }^{\mathrm{a}, \mathrm{b}, *}$, Karin Johst ${ }^{\mathrm{b}}$, Thomas Banitz ${ }^{\mathrm{b}}$, Mike S. Fowler ${ }^{\mathrm{c}}$, Jürgen Groeneveld ${ }^{\mathrm{b}}$, \\ Alvaro G. Gutiérrez ${ }^{\mathrm{d}}$, Florian Hartig ${ }^{\mathrm{e}}$, Rainer M. Krug ${ }^{\mathrm{f}}$, Matthias Liess ${ }^{\mathrm{g}, \mathrm{h}}{ }^{\text {, Glenn Matlack }}{ }^{\mathrm{i}}$, \\ Katrin M. Meyer ${ }^{\mathrm{j}}$, Guy Pe'er ${ }^{\mathrm{k}}$, Viktoriia Radchuk ${ }^{\mathrm{a}, 1}$, Ana-Johanna Voinopol-Sassu ${ }^{\mathrm{m}}$, \\ Justin M.J. Travis ${ }^{\mathrm{n}}$ \\ ${ }^{a}$ German Centre for Integrative Biodiversity Research (iDiv) Halle-Jena-Leipzig, Deutscher Platz 5e, 04103 Leipzig, Germany \\ ${ }^{\mathrm{b}}$ Helmholtz Centre for Environmental Research - UFZ, Department of Ecological Modelling, Permoserstraße 15, 04318 Leipzig, Germany \\ ' Department of Biosciences, College of Science, Swansea University, Singleton Park, Swansea SA2 8PP, UK \\ d Departamento de Ciencias Ambientales y Recursos Naturales Renovables, Facultad de Ciencias Agronómicas, Universidad de Chile, Santa Rosa 11315, La \\ Pintana, Santiago, Chile \\ e University of Freiburg, Department of Biometry and Environmental System Analysis, Tennenbacherstrasse 4, 79106 Freiburg, Germany \\ ${ }^{\mathrm{f}}$ Centre for Invasion Biology (C.I.B), Department of Botany and Zoology, Stellenbosch University, Private Bag x1, Matieland 7602, South Africa \\ ${ }^{g}$ Helmholtz Centre for Environmental Research - UFZ, Department of System-Ecotoxicology, Permoserstraße 15, 04318 Leipzig, Germany \\ ${ }^{\mathrm{h}}$ RWTH Aachen University, Institute for Environmental Research (Biology V), Worringerweg 1, 52074 Aachen, Germany \\ i Department of Environmental and Plant Biology, Porter Hall, Ohio University, Athens, $\mathrm{OH} 45701$, USA \\ j University of Göttingen, Ecosystem Modelling, Büsgenweg 4, 37077 Göttingen, Germany \\ ${ }^{\mathrm{k}}$ Helmholtz Centre for Environmental Research - UFZ, Department of Conservation Biology, Permoserstraße 15, 04318 Leipzig, Germany \\ ${ }^{1}$ Leibniz Institute for Zoo and Wildlife Research (IZW), Alfred-Kowalke-Straße 17, 10315 Berlin, Germany \\ $\mathrm{m}$ School of Biological Sciences, University of Canterbury, Private bag 4800, Christchurch 8140, New Zealand \\ ${ }^{\mathrm{n}}$ Institute of Biological and Environmental Sciences, University of Aberdeen, Aberdeen AB24 2TZ, UK
}

\section{A R T I C L E I N F O}

\section{Article history:}

Available online 17 December 2015

\section{Keywords:}

Prediction

Bias

Precision

Species interaction

SDM

Protocol

Uncertainty

\begin{abstract}
A B S T R A C T
Environmental change is expected to shift the geographic range of species and communities. To estimate the consequences of these shifts for the functioning and stability of ecosystems, reliable predictions of alterations in species distributions are needed. Projections with correlative species distribution models, which correlate species' distributions to the abiotic environment, have become a standard approach. Criticism of this approach centres around the omission of relevant biotic feedbacks and triggered the search for alternatives. A new generation of mechanistic process-based species distribution models aims at implementing formulations of relevant biotic processes to cover species' life histories, physiology, dispersal abilities, evolution, and both intra- and interspecific interactions. Although this step towards more structural realism is considered important, it remains unclear whether the resulting projections are more reliable. Structural realism has the advantage that geographic range shifting emerges from the interplay of relevant abiotic and biotic processes. Having implemented the relevant response mechanisms, structural realistic models should better tackle the challenge of generating projections of species responses to (non-analogous) environmental change. However, reliable projections of future species ranges demand ecological information that is currently only available for few species. In this opinion paper, we discuss how the discrepancy between demand for structural realism on the one hand and the related knowledge gaps on the other hand affects the reliability of mechanistic species distribution models. We argue that omission of relevant processes potentially impairs projection accuracy (proximity of the mean outcome to the true value), particularly if species range shifts emerge from species and community dynamics. Yet, insufficient knowledge that limits model specification and parameterization, as well as process complexity,
\end{abstract}

\footnotetext{
Abbreviations: C-SDM, correlative species distribution model; H-SDM, hybrid species distribution model; M-SDM, mechanistic species distribution model.

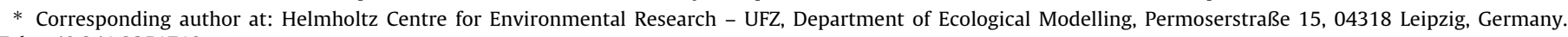
Tel.: +493412351718.

E-mail address: alexander.singer@ufz.de (A. Singer).
} 
increases projection uncertainty (variance in the outcome of simulated model projections). The accuracy-uncertainty-relation reflects current limits to delivering reliable projections of range shifts. We propose a protocol to improve and communicate projection reliability. The protocol combines modelling and empirical research to efficiently fill critical knowledge gaps that currently limit the reliability of species and community projections.

(C) 2015 Elsevier B.V. All rights reserved.

\section{Introduction}

Climate change, in conjunction with other anthropogenic drivers, affects species and ecological communities. Projections (see Table 1) of the resulting consequences for species distributions and community dynamics are challenging and represent a knowledge frontier (Doak et al., 2008). At the same time, to sustain biodiversity and ecosystem services Loreau (2010), the demand for projections of ecosystem dynamics in changing environments will continue to increase. We need predictive models that provide reliable projections into the future, to inform and support decisionmaking and policy under rapidly changing conditions (Leadley et al., 2014; Mouquet et al., 2015; Thuiller et al., 2013).

To be reliable, model projections must be accurate and must minimize uncertainty (Table 1): "Accuracy" describes how closely model projections approximate a true value in the real system (Table 1). If accurate projections are repeated they will cluster around the true value. Accuracy might be estimated from model validation against true values in past and current situations. Unfortunately, the true value is unknown for future projections. Therefore, quantifying accuracy of future projections is impossible.

"Uncertainty" describes the level of variability among repeated model projections (Table 1 ). The more widespread the results of repeated projections are, the more uncertain we regard them. Uncertainty depends on the consideration, implementation, and parameterization of processes in a model. As processes can vary among model implementations, projection uncertainty can vary among models. Therefore, projection uncertainty is a model property that can be quantified within the remits of the model.

The above concepts do not allow quantifying reliability, as we cannot quantify accuracy of future projections, and can approximate full uncertainty only to the degree of the projection uncertainty of alternative model implementations and parametrizations. But the concepts allow us to identify potentially unreliable projections, i.e. projections that are potentially inaccurate or uncertain. Projections are uncertain, if the model outcome shows broad variance. Projections should be expected to be inaccurate, if they result from models that lack detail, even though the detail's relevance (Table 1) for model projections is known or should be expected according to prior knowledge or theory.

In this opinion paper we discuss, whether reliable projections of species and community responses to climate change can be achieved given current knowledge; and how projection reliability can be improved within a frame of modelling and empirical research that aims at enhancing information. We particularly address species range shifts, where species need to track the geographic shift of their suitable climatic conditions (Chen et al., 2011; Hickling et al., 2006; Parmesan et al., 1999). We focus on species range shift projections, because of the growing interest in informing conservation policy of the potential risks of climate change to biodiversity (e.g. Root et al., 2003; Walther et al., 2005) and the repeated call for reliable predictions and decision-support. However, our arguments are also applicable to other areas of predictive modelling (Martin et al., 2015; Matthiopoulos et al., 2015), especially in the context of rapid, mixed environmental changes.

Several approaches exist to project the impact of climate change on the shifting of species distributions, with correlative species distribution models (C-SDMs; also known as niche or climate envelope models) and highly mechanistic species distribution models (M-SDMs; also known as process-based models) being at the opposite ends of a gradient (Dormann et al., 2012).

The correlative approach relates observed geographical species distributions to local environmental conditions (Guisan and Zimmermann, 2000), following the assumption that the climatic and environmental niche is the major factor determining species range (Woodward and Williams, 1987). Subsequently, C-SDMs project future species distributions according to projected climate change, assuming that species either might disperse infinitely and immediately follow change in climatic conditions, or that they cannot disperse and therefore are restricted to future suitable areas within their current range (e.g. summarized by Engler and Guisan, 2009).

In the recent hybrid modelling approach (H-SDM), C-SDMs are enriched by consideration of additional ecological knowledge. $\mathrm{H}$ SDMs usually start with niche estimates from C-SDMs and in the next step add single or few selected biotic factors or processes (Dormann et al., 2012), usually in a form that phenomenologically aggregates effects of underlying mechanisms. Examples are the inclusion of demography (Dullinger et al., 2012; Swab et al., 2015), the inclusion of the spatial distribution of interacting species to account for interspecific interactions (Kissling et al., 2010; Meier et al., 2010; Schweiger et al., 2008) or the consideration of species' dispersal abilities (Boulangeat et al., 2012; Buse and Griebeler, 2011; De Cáceres and Brotons, 2012; Engler and Guisan, 2009; Meier et al., 2012).

M-SDMs go a step further by including detailed abiotic and biotic processes that mechanistically describe individual, species or community responses to climate change (e.g. Bocedi et al., 2014; Chuine and Beaubien, 2001; Kearney et al., 2008; Lischke et al., 2006; Scheller and Mladenoff, 2008). In forward simulations of M-SDMs, spatiotemporal dynamics of species range shifts emerge from the interplay of the biotic processes. The concept of M-SDMs follows the assumption that details about biotic interactions cannot be ignored when modelling responses to climate change. Lurgi et al. (2015) review types of M-SDM frameworks and their properties.

For reasons of clarity, in this paper, we do not treat H-SDMs as an own category, but concentrate on the two extremes C-SDMs and M-SDMs. H-SDMs can be considered either as enhancements of CSDMs, if they consider biotic factors in a correlative approach, or as low-level M-SDMs, if they include single simplistic biotic processes. Generally, there is a continuum of structural realism, with some models including more, some less processes (Dormann et al., 2012).

Due to their methodological and structural differences, C-SDMs and M-SDMs are suitable for different aspects of species distribution modelling. C-SDMs are designed to exploit widely available data (e.g. species occurrence databases, spatial climatic variation). By contrast, M-SDMs are particularly well equipped to include detailed biotic processes (e.g. on species interactions, demography, dispersal, or physiology), but their parameterization is hard because of the lack of detailed ecological data (e.g. demographic rates). We argue that these technical differences, with respect to the inclusion of biotic processes and model parameterization, affect projection reliability. 
Table 1

Glossary.

\begin{tabular}{|c|c|}
\hline True value & $\begin{array}{l}\text { - Realized value (of an ecosystem state variable) in } \\
\text { the natural system. Measurement of a current or } \\
\text { past true value is limited by measurement } \\
\text { reliability. A future true value is unknown }\end{array}$ \\
\hline Available knowledge & $\begin{array}{l}\text { - All available information about a natural system, } \\
\text { its responses to the environment and } \\
\text { environmental change, and about the environment } \\
\text { itself (for example observed data, expert } \\
\text { knowledge or ecological theory). Available } \\
\text { knowledge additionally includes information } \\
\text { about lack of knowledge }\end{array}$ \\
\hline Projection & $\begin{array}{l}\text { - Any description of the future and the pathway } \\
\text { leading to it }\end{array}$ \\
\hline Model projection ${ }^{\mathrm{a}}$ & $\begin{array}{l}\text { - Outcome of a model that provides potential } \\
\text { future responses to environmental change. Model } \\
\text { projections may also be used for forecasting } \\
\text { (projections over short time horizons) }\end{array}$ \\
\hline Prediction $^{\mathrm{a}}$ & $\begin{array}{l}\text { - When a projection is branded "most likely" it } \\
\text { becomes a prediction }\end{array}$ \\
\hline $\begin{array}{l}\text { Accuracy of a } \\
\text { projection }\end{array}$ & $\begin{array}{l}\text { - The proximity of the mean projected value to the } \\
\text { true value. If the estimation procedure is repeated } \\
\text { and the mean of the values of all repetitions is near } \\
\text { the true value then accuracy is high, otherwise } \\
\text { accuracy is low. } \\
\text { Accuracy of a projection towards the future cannot } \\
\text { be quantified, because the future true value is } \\
\text { unknown. Nevertheless, true values of the past can } \\
\text { be used to inform models }\end{array}$ \\
\hline $\begin{array}{l}\text { Uncertainty of a } \\
\text { projection }\end{array}$ & $\begin{array}{l}\text { - The variability of the projected values. If the } \\
\text { estimation procedure is repeated and the values } \\
\text { differ considerably then uncertainty is high } \\
\text { (imprecise estimates). If the repetitions yield very } \\
\text { similar projected values then uncertainty is low } \\
\text { (precise estimates). Projection uncertainty can be } \\
\text { quantified in terms of the output distribution of } \\
\text { the projective model. Yet, projection uncertainty is } \\
\text { a model property and therefore depends on the } \\
\text { specific model implementation and } \\
\text { parameterization }\end{array}$ \\
\hline $\begin{array}{l}\text { Reliability of a } \\
\text { projection }\end{array}$ & $\begin{array}{l}\text { - The reliability of a projection is high if accuracy is } \\
\text { high and uncertainty is low. } \\
\text { Reliability cannot be quantified, due to the limits } \\
\text { in quantification of accuracy or uncertainty. Yet, } \\
\text { the concept allows identifying, when a projection } \\
\text { cannot be relied on. } \\
\text { A projection is potentially unreliable, if at least one } \\
\text { of the two conditions is fulfilled: } \\
\text { (1) projection accuracy cannot be trusted } \\
\text { (2) the projection is uncertain }\end{array}$ \\
\hline $\begin{array}{l}\text { Relevance of processes } \\
\text { or factors }\end{array}$ & $\begin{array}{l}\text { - Importance of a process or factor to explain } \\
\text { variability in model projections. Relevance } \\
\text { depends on the change in conditions for which a } \\
\text { response is projected. Further, relevance of a } \\
\text { specific process or factor can vary among projected } \\
\text { model outcome variables }\end{array}$ \\
\hline Structural realism & $\begin{array}{l}\text { - The amount of considered reality in a model in } \\
\text { terms of correctly specified mechanisms and } \\
\text { processes considered relevant for the projection. } \\
\text { This definition extends the formulation used in the } \\
\text { context of pattern-oriented modelling (Grimm and } \\
\text { Railsback, 2012), because it includes processes that } \\
\text { cannot be motivated by the available patterns. This } \\
\text { extension acknowledges that scarcity of patterns, } \\
\text { should not rule out potentially relevant processes. } \\
\text { Instead our definition stimulates enhancement of } \\
\text { the evidence base that is required to understand } \\
\text { process relevance }\end{array}$ \\
\hline Emergence & $\begin{array}{l}\text { - Dynamics and patterns that are not imposed } \\
\text { explicitly in the model, but result from the } \\
\text { interplay of processes included in the model. The } \\
\text { final outcome at the system level emerges from } \\
\text { this interplay }\end{array}$ \\
\hline
\end{tabular}

a We have partly adopted definitions from the is-enes project: http:// climate4impact.eu/impactportal/help/faq.jsp?q=scenarios_projections_ predictions_forecasts.
In the following, we give an overview of how biotic processes influence species distributions and their response to climate change. We then conceptualize how inclusion of biotic processes and their interplay alters projection reliability. Finally, we discuss implications for the reliability of species range projections and suggest a strategy towards more reliable projections.

\section{Processes driving species and community distributions}

Biotic factors impact species and community distributions and range shifts. Theoretical and empirical studies have demonstrated the relevance of demographic processes (Pagel and Schurr, 2012), physiology (Fordham et al., 2013; Kearney et al., 2008; Kearney and Porter, 2009; Morin et al., 2007, 2008), dispersal abilities (Travis et al., 2013; Best et al., 2007; Zurell et al., 2012), intraspecific variability across spatial scales (e.g. in demographic rates (Swab et al., 2015)), local adaptation (Atkins and Travis, 2010; Bocedi et al., 2013; Bourne et al., 2014), evolution (e.g. changes in genetic variety along the gradient from core to range margin (Bocedi et al., 2014; Cobben et al., 2011; Hill et al., 2011), enhancement of dispersal traits (Hill et al., 2011; Thomas et al., 2001) and habitat as well as host plant switch (Thomas et al., 2001)), intraspecific density dependence (Best et al., 2007; Münkemüller et al., 2011) and interspecific interactions (Brooker et al., 2007; Kissling et al., 2010; Menendez et al., 2008; Münkemüller et al., 2009; Singer et al., 2013; Svenning et al., 2014).

Species and community responses to climate change are driven by interacting dynamics of the environment, the species and the community (e.g. Blois et al., 2013; Higgins et al., 2012; Moir et al., 2014 and references therein; Thuiller et al., 2013; Walther, 2010 - Figure 1). Spatiotemporal dynamics of the abiotic environment (green box in Fig. 1) via species (blue box) and community dynamics (red box) alter species and community distributions (grey box).

Spatiotemporal environmental changes include land-use or climate change (e.g. Bellard et al., 2012), short-term environmental stochasticity (e.g. Ripa and Heino, 1999), anthropogenic influences (e.g. by pesticides Liess et al., 2008), or natural disturbance (e.g. Johst and Drechsler, 2003). These processes operate on different spatial and temporal scales and are often the result of drivers external to the ecological system, although some feedbacks from ecosystems can exist (Blois et al., 2013), for example effects of vegetation on climate (Bonan, 2008).

Environmental dynamics directly affect species-specific spatiotemporal dynamics (blue boxes in Fig. 1). Particular species response dynamics (e.g. reviewed in Parmesan, 2006) are geographic range (Chen et al., 2011; Jump et al., 2012; Lenoir et al., 2008; Parmesan and Yohe, 2003) or phenology shifting (Memmott et al., 2007; Saino et al., 2011). Species dynamics may also involve micro-evolutionary processes (Bellard et al., 2012; Travis et al., 2009) or even population extinction (Johst and Wissel, 1997; Ripa and Heino, 1999; Fowler and Ruokolainen, 2013; Urban, 2015).

Species level dynamics are governed by species traits and population processes (as indicated in the small blue boxes in Fig. 1). Importantly, these key processes can interact substantially with climate change. For example, climate change can have both direct and indirect impacts on the dispersal behaviour or capacities of individuals (Travis et al., 2013).

Even more complex are spatiotemporal dynamics at the community level (upper red boxes in Fig. 1). Processes influencing community dynamics include interspecific interactions or coevolution. Interspecific interactions can directly respond to climate change (Blois et al., 2013). Environmental change can alter existing species interactions (Laws and Joern, 2013; Stenseth et al., 2015), alter the extinction risk of populations and species within communities (Ruokolainen and Fowler, 2008) or even change the type 


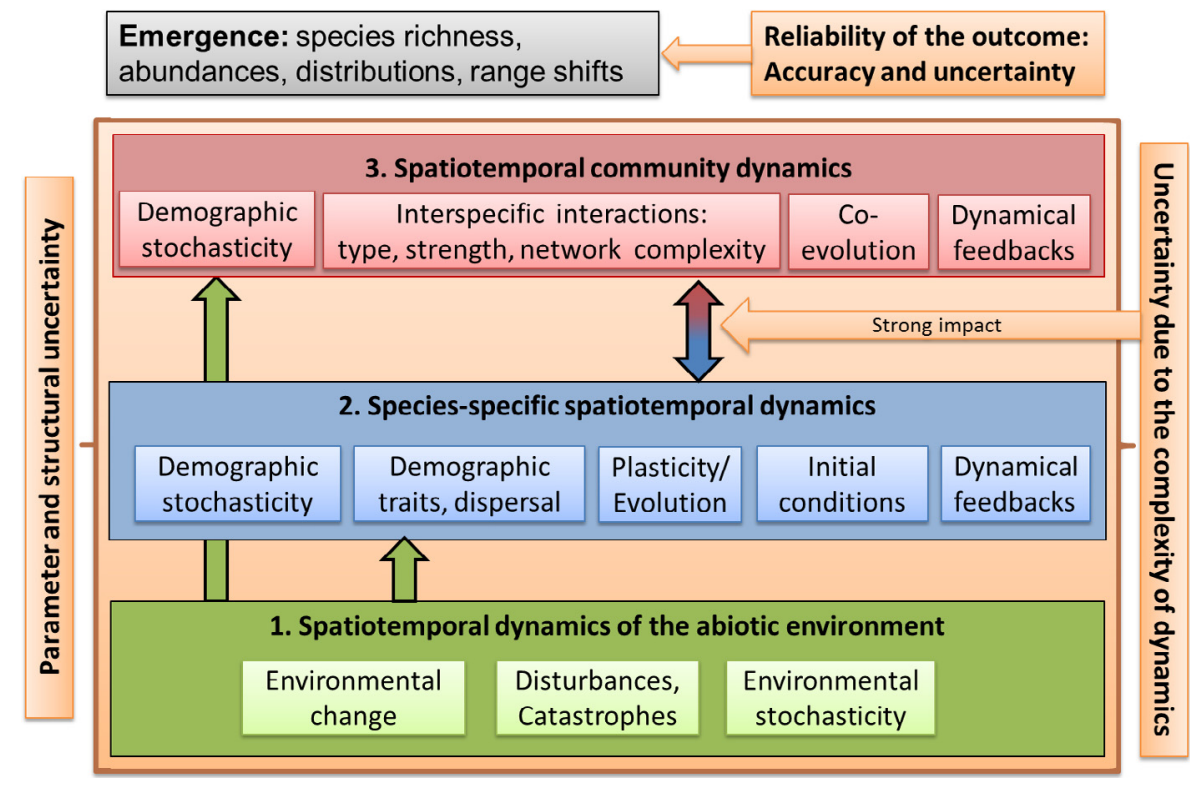

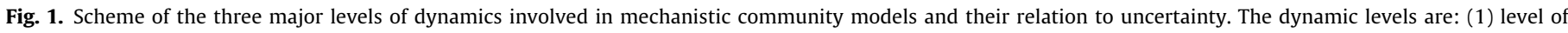

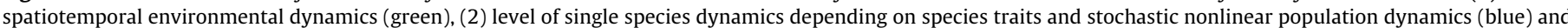

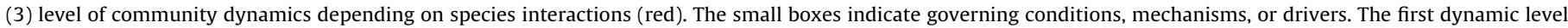

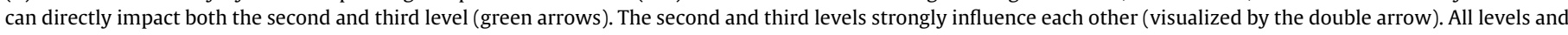

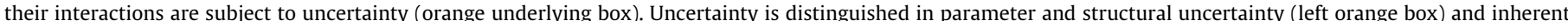

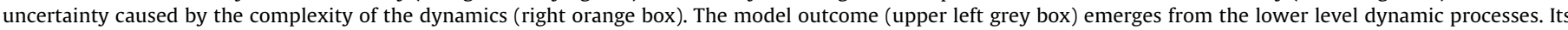

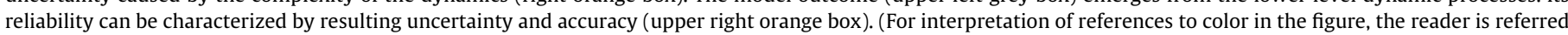
to the web version of the article.)

of interactions between species (Travis et al., 2006). Even more important, however, are the indirect responses of communities to changes in presence or species-specific dynamics of any of the interacting species (e.g. Norberg et al., 2012; Sanders and van Veen, 2011; coloured arrow from second to third level in Fig. 1). Because species respond differently to environmental change (Davis, 1981; Voigt et al., 2003; Zurell et al., 2009; Stenseth et al., 2015), changes in range and phenology alter not only the spatiotemporal distribution of single species but also the character of interspecific interactions (Zarnetske et al., 2012).

Communities might be disassembled due to range mismatch (Polce et al., 2014; Schweiger et al., 2008) or newly assembled due to invasions (Anderson et al., 2014; Svenning and Condit, 2008). Phenology mismatches, caused by asynchronous phenological shifts, might disrupt species interactions even when species still co-occur (Bartomeus et al., 2011; Hegland et al., 2009; Memmott et al., 2007), or generate new species interactions (Hobbs et al., 2009; Pateman et al., 2012).

Community dynamics also feed back into intraspecific dynamics (Blois et al., 2013), indicated by the coloured double arrow linking third and second level in Fig. 1. As a result, community processes potentially change relative abundances and species co-occurrences, leading to changes in strength, form and number of intraspecific interactions. The feedback between inter- and intraspecific dynamics can yield a rich variety of community responses to climate change (Bocedi et al., 2013). These still need to be explored, since they remain poorly understood.

\section{How does the consideration of biotic processes impact projection reliability of species and community models?}

We suggest that the inclusion of biotic processes in models of species and community responses to environmental change has three main consequences:
(1) Inclusion of relevant processes enhances structural realism, and reflects the mechanistic knowledge about the ecological system. Increase of structural realism can improve model accuracy. However (2), the available ecological knowledge (e.g. reviewed in Thuiller et al., 2013) might be insufficient to fully describe relevant processes that should be implemented, leaving us with parameter and structural uncertainty (left orange box in Fig. 1; Table 2). (3) The additional complexity caused by the interplay of coupled stochastic processes results in inherent uncertainty (right orange box in Fig. 1). Below we explain these consequences in more detail, with specific sources of uncertainty described in Table 2.

\subsection{Accuracy due to increased structural realism}

Structurally realistic models have several advantages: (1) the processes capture causal relations of principal ecological mechanisms that govern responses of species and communities to environmental change, (2) from these mechanisms spatiotemporal population dynamics and therefore species and community dynamics (such as range shifts) emerge (DeAngelis and Mooij, 2005), and (3) the principal ecological mechanisms and the model's emergent properties are assumed to be invariant under environmental change, which makes structurally realistic models suitable for extrapolations to new environmental conditions, such as climate change (Buckley et al., 2010; Schurr et al., 2012).

For these reasons, it can be expected that increased structural realism enhances the model's projection accuracy, i.e. an average model projection should be closer to the true value. In contrast, omission of a process that is known to affect the dynamic response of a species or community to environmental change (e.g. dispersal) can corrupt the accuracy of model projections. This can be counteracted by testing plausible alternative model structures for their consequences on projection accuracy. 
Table 2

Processes and factors impacting uncertainty in species and community distribution modelling.

\begin{tabular}{|c|c|}
\hline Sources & Description, examples \\
\hline \multicolumn{2}{|l|}{ 1. Parameter and structural uncertainty } \\
\hline Parameter uncertainty & $\begin{array}{l}\text { - Uncertainty in parameter values of all factors and processes involved; limited data availability (e.g. } \\
\text { on species niche differences, temperature or precipitation change); uncertainty in data (e.g. in species } \\
\text { distribution data); missing data }\end{array}$ \\
\hline Structural uncertainty in environmental processes & $\begin{array}{l}\text { - Uncertainty about which abiotic environmental factors and processes are essential for the species } \\
\text { and communities }\end{array}$ \\
\hline Structural uncertainty in population processes & $\begin{array}{l}\text { - Uncertainty about (1) which population dynamic processes are essential; ( } 2 \text { ) the type and/or } \\
\text { structure of intraspecific interactions; ( } 3 \text { ) entrance points of the abiotic environmental effects } \\
\text { concerning life history parameters and intraspecific interactions }\end{array}$ \\
\hline Structural uncertainty in community processes & $\begin{array}{l}\text { - Uncertainty about (1) which community dynamic processes are essential; ( } 2 \text { ) the type and/or } \\
\text { structure of interspecific interactions (e.g. mutualism or commensalism, unknown attributes of food } \\
\text { web structure); (3) unknown functional responses; (4) how external drivers impact interspecific } \\
\text { interactions }\end{array}$ \\
\hline \multicolumn{2}{|l|}{ 2. Uncertainty due to the complexity of dynamics } \\
\hline Environmental and demographic stochasticity & $\begin{array}{l}\text { - Random events may lead to completely different communities (e.g. stochastic trajectories of } \\
\text { succession); they influence population dynamics and extinction risk; may impact population cycles, } \\
\text { altering timing and intensity of the dynamics of interacting species; determine colonization/ } \\
\text { extinction patterns, founder effects and selection }\end{array}$ \\
\hline Intra- and interspecific interactions; biotic feedbacks & $\begin{array}{l}\text { - Multiple interactions and feedbacks inflate uncertainty in ecological networks; existence of } \\
\text { alternative stable states can cause changes in species abundance, dynamics and composition; } \\
\text { propagation of uncertainty; dependency of dynamics and future system states on initial conditions/ } \\
\text { system's history }\end{array}$ \\
\hline Transient dynamics & $\begin{array}{l}\text { - Pulse, press or ramp perturbations disturb population and community dynamics; transients are } \\
\text { dictated by biotic interactions; may cause differences in short-term vs. long-term observations, } \\
\text { time-lags (slow reaction to external change), or (extreme) fluctuations in species or community } \\
\text { metrics }\end{array}$ \\
\hline Trait and individual variability & $\begin{array}{l}\text { - Intraspecific genetic/ phenotypic plasticity can lead to completely different communities (e.g. } \\
\text { switches to hosts previously not available) }\end{array}$ \\
\hline Evolution & - Evolution alters species traits during range shifting; evolutionary rescue effects \\
\hline
\end{tabular}

\subsection{Parameter and structural uncertainty}

Model processes have to be described and parameterized. Knowledge gaps will introduce uncertainty at all three dynamical levels (e.g. Zurell et al., 2012; left orange box in Fig. 1).

At the species level, large empirical and synthesis efforts now aim at filling knowledge gaps (Lavorel and Garnier, 2002; Violle and Jiang, 2009). Examples include databases covering a range of traits for a large number of plant (e.g. Kattge et al., 2011) or animal species (Jones et al., 2009). Other databases collect species needs (e.g. area requirement, see Pe'er et al., 2014), and life history transition models (Salguero-Gómez et al., 2015).

Besides parameter uncertainty, there is uncertainty about the structure of processes. Structural uncertainty includes e.g. the way environmental drivers impact on species demographic parameters (Johst et al., 2013; Radchuk et al., 2013; Ruokolainen and Fowler, 2008), the shape of species' dispersal kernels (Higgins et al., 2003) or the hierarchical organization of environmental and landscape structure (Matlack and Leu, 2007).

In the context of community projections, the parameter space increases together with increasing species number, because the interactions between species have to be described and parameterized as well as intraspecific traits. (Estimation of intraspecific parameters in the absence of interacting species will likely generate erroneous predictions.) Methods have been suggested to reduce the dimensionality of the parameter space (Kissling et al., 2012). Among them topological (Binzer et al., 2011; Dunne et al., 2002) and dynamical interaction network analyses (Bastolla et al., 2009; Thébault and Fontaine, 2010), currencies or regulating factors (Barabás et al., 2014), and community modules (Gilman et al., 2010) support the use of dynamic community models.

While some structural aspects of communities might be relatively well known (e.g. their topological 'foodweb' structure), we are less informed about other features, for example the type or functional form of interspecific interactions (facilitation versus competition, symmetric versus asymmetric competition, stabilizing versus equalizing structuring of communities (Chesson, 2000)).
Even less is known about the way in which environmental drivers impact species interactions, which is only recently becoming an increasingly important research topic (Barabás et al., 2014; Stenseth et al., 2015).

\subsection{Uncertainty due to the complexity of dynamics}

\subsubsection{Uncertainty due to stochastic events or biotic feedback processes}

Generally, stochastic dynamics coupled with dynamic feedbacks generate inherent uncertainty (Higgins et al., 2003; Petchey et al., 2015). Therefore, community dynamic responses to environmental change can be highly variable.

Fig. 2 displays an illustrative example of two interacting species and their coupled nonlinear responses to an environmental driver. Depending on the driver's strength and variability, the nonlinear responses of species A and B will be weak or strong and the variability amplified or dampened. The situation will often be even more complex, as species may directly respond to the environmental driver and to each other.

Stochastic processes introduce variance. This variance changes while propagated through population and community dynamic processes. Depending on the processes, the impact of stochastic variance might be amplified (Greenman and Benton, 2003) or reduced leading to increased or reduced projection uncertainty (Donalson and Nisbet, 1999). More critically, parameter uncertainty or stochastic events can trigger alternative system states (Van Nes and Scheffer, 2003). For example due to founder effects, the random early arrival of one species on a site might provide the essential advantage to outcompete later arriving species (Geange and Stier, 2009). As it is unknown, which species by chance will be first to colonize a site, this uncertainty cannot be reduced and may result in highly uncertain projections of species or community responses, even if the ecological system is known to a high degree of detail. Strong and multiple coupling of stochastic dynamics and biotic feedbacks is typical for community responses to environmental change (see Fig. 1). 


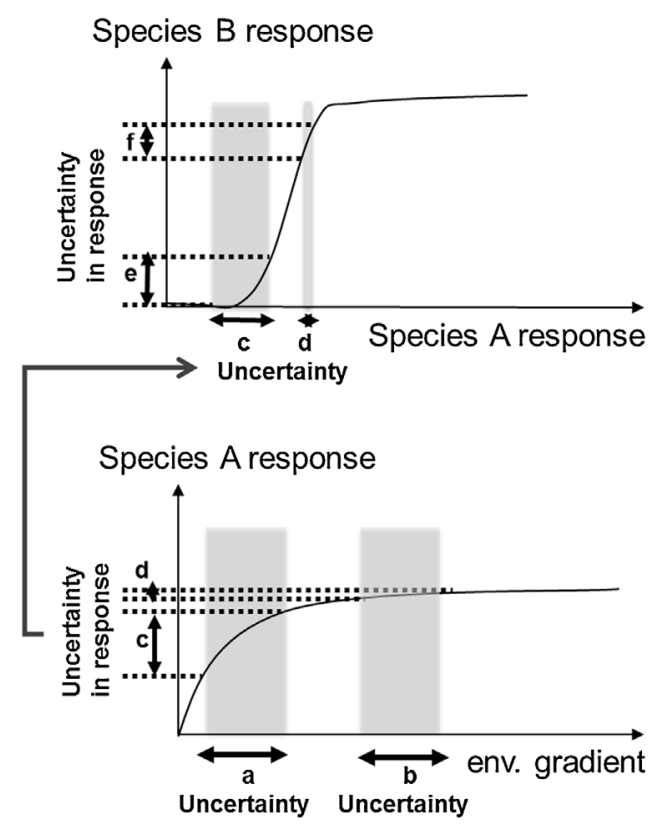

Fig. 2. Scheme of uncertainty due to twofold nonlinear relationships. The non-linear relationships are exemplified by a monod response of species $A$ to the environment and a sigmoid response of species $B$ to species A. Uncertainty in the strength of the environmental driver (schematically displayed as grey boxes in the bottom panel) leads to uncertainty in the response of species A to this driver depending on the nonlinear shape of the species response curve (black solid line). If the driver is weak (a), uncertainty in the driver value causes high uncertainty in species A's response to the driver (c). If the driver is strong (b), but uncertainty in the driver remains the same as before, uncertainty in the response of species $A$ is lower (d). Further, if species $A$ affects species $B$ the environmental change may also influence species $B$ even if species B itself is not directly impacted, through environmental filtering. The response of species $B$ to species $A$ introduces another nonlinear relationship that propagates the uncertainty in species $A$ response $(c, d)$ to uncertainty in species $B$ response $(e, f)$.

\subsubsection{Uncertainty due to transient dynamics}

Responses to environmental changes are inherently transient (e.g. Singer et al., 2013; Snell et al., 2014), and disturbances keep many ecological systems in a transient state (as collated in Pickett and White, 1985). Environmental conditions (e.g. temperature) may continuously change over long time periods with ongoing effects on the population and community dynamics. But even short disturbance events can cause long lasting transient phases, depending on the type of population dynamics and the number and type of interspecific interactions (Hastings, 2004; Liess and Foit, 2010). Transient dynamics can involve stronger temporal variance in species and community dynamics than expected for a stable community, e.g. sudden disease outbreaks after invasion of an additional host species (Singer et al., 2009).

Transient dynamics are sensitive to demographic and environmental stochasticity that can shift community dynamics towards one of the several alternative equilibrium states. The long-term response might not be predictable from transient system behaviour as demonstrated by Fukami and Nakajima (2011). One area where transient dynamics are extremely important is projection of the spread of invasive species (Václavík and Meentemeyer, 2012).

\subsubsection{Uncertainty due to individual variability and evolution}

Variability among individuals within a species can be an important factor in shaping and shifting species responses to environmental change (Albert et al., 2011; Swab et al., 2015; see Moran et al., 2016 for a recent review).

Modelling studies have demonstrated impacts of range change on evolution and genetic diversity (reviewed by Kopp and Matuszewski, 2014). Neutral and even deleterious mutations at the

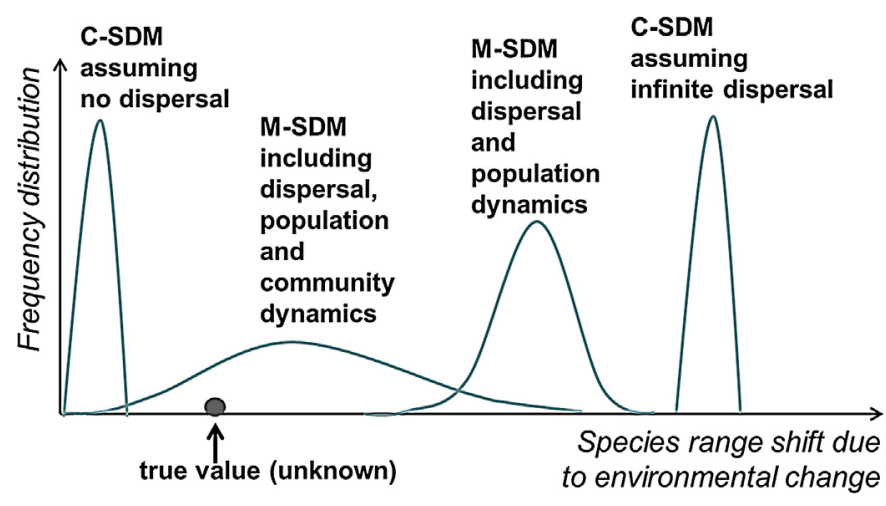

Fig. 3. Schematic figure characterizing the projection reliability for a species geographic range shift (C-SDM, correlative species distribution model; M-SDM, mechanistic species distribution model). The position of distributions relative to the true value (point on $x$-axis) indicates projection accuracy. The shape of the distributions illustrates projection uncertainty assuming the consideration of all sources of uncertainty (Table 2). We exemplarily display assumed range projections for a species with intermediate dispersal that is reliant on the presence of another species.

leading edge of expanding populations can survive for considerable time (Travis et al., 2007), while total neutral genetic diversity in range shifting species declines (Cobben et al., 2011). Further, the evolution of life history traits such as reproduction rate or competitive ability may be triggered and influenced by climate change (Burton et al., 2010; Hill et al., 2011; Thomas et al., 2001), and evolutionary processes can operate within ecological time scales ((Hendry et al., 2007).

There is little understanding of the impacts of individual variability and evolutionary processes in the interplay with dynamical feedbacks on range dynamics. Theoretical studies suggest their importance (e.g. Bocedi et al., 2013; Cobben et al., 2012; Valladares et al., 2014). Nevertheless, individual variability and evolutionary processes are often poorly recognized in projections of future communities (Evans et al., 2013), with potential effects on projection reliability.

\section{Projection reliability of species and community distributions}

The dilemma for achieving reliable species and community projections under climate change is as follows: On the one hand, all relevant landscape and biotic processes must be included to be structurally realistic and to avoid potentially inaccurate model projections. On the other hand, inclusion of processes that are insufficiently informed increases projection uncertainty and might corrupt accuracy. Thus, model projections are unreliable, if potentially relevant processes are missing or if relevant processes are included that cannot be sufficiently parameterized due to lack of data.

Fig. 3 schematically illustrates projection reliability from approaches that incorporate or omit relevant biotic processes. For the scheme, we assume a species that responds to changes in climate by shifting its geographic range. The species can disperse over medium distances and is reliant on another species.

The C-SDM is calibrated to the species abiotic niche. Implementation of biotic processes in a C-SDM is technically difficult. To consider dispersal, we retract to a common and technically feasible approach: We display two C-SDM projections differing in the assumption that the species either cannot disperse (left C-SDM distribution) or that it can immediately follow the changes in abiotic conditions (right C-SDM distribution). Assuming the latter, the projected range shift is remote from the true value. Assuming no dispersal, the C-SDM projection is closer to the true value. 
However, its underestimation of the species dispersal ability has effects similar to those of the interspecific interaction that in fact limits the species range shift. Thus, accuracy is achieved for the wrong reason.

M-SDMs that include population dynamic processes and species traits (in Fig. 3 schematically depicted for the medium dispersal ability) should predict more accurately (resulting in a distribution of outcomes closer to the true value). Yet, Fig. 3 illustrates that model accuracy is still low, because a relevant process is missing: the interspecific interaction. Adding this process to the M-SDM provides the highest chance to encompass the true value.

Projection uncertainty varies between the C-SDM and M-SDM approach (as visualized in Fig. 3). According to C-SDM projections uncertainty is seemingly low. M-SDM projections convey higher uncertainty because they consider additional sources of uncertainty (orange boxes in Fig. 1 and Table 2). Given the trade-off between accuracy and uncertainty, we propose that reliable projections of the species range cannot be achieved from currently available knowledge.

\subsection{Projection reliability of different methodological approaches to model range shifting}

Different approaches have been developed to cope with the current lack of detailed ecological knowledge, which presents the key limitation to reliable projections.

C-SDMs take a common approach to circumvent knowledge gaps. They revert to available knowledge. Available for many species is data on spatial occurrence and the spatial distribution of environmental conditions. C-SDMs are particularly well developed to analyze such spatial data. However, it is technically hard to incorporate biotic processes. Therefore, projections made by C-SDMs may lack accuracy or achieve accuracy for the wrong reasons (as visualized in Fig. 3). Projection accuracy for C-SDMs is reduced for example if the species are not in equilibrium with their environmental conditions during data collection or their abiotic niche cannot be filled due to constraints from biotic processes (Dormann, 2007; Guisan and Thuiller, 2005). Zurell et al. (2009) found that accuracy of correlative models depends on ecological circumstances and the transience of population dynamics. C-SDMs should be accurate if a species range is largely determined by the species physiological requirements, which in the correlative model can be approximated by abiotic environmental factors - but evidence shows that this is rarely the case (Keil et al., 2012).

Apart from accuracy, we expect the projection uncertainty of CSDMs to be small in comparison to the uncertainty that is contained in the knowledge about the ecological system. The limited outcome uncertainty (Fig. 3) usually comprises model-based uncertainty from variance among statistical methods, measurement errors in the input data, and uncertainty about future environmental conditions (Gould et al., 2014; Guisan et al., 2006; Thuiller, 2004; Thuiller et al., 2004). In sum, C-SDMs bear the risk of overestimating or underestimating species' range shift capacities, and of underestimating the true uncertainty because they ignore the complexity of biotic processes and related knowledge gaps.

$\mathrm{H}$-SDMs overcome some of the technical limitations of C-SDMs (e.g. Guisan and Thuiller, 2005). for specific ecological situations, where additional ecological knowledge is available. Gallien et al. (2010) suggest that H-SDMs provide reliable projections for the spread of invasive species, if processes are selected firstly for their relevance but ultimately according to the sufficient availability of data for their parameterization. This approach can keep control on projection uncertainty, but the omission of relevant processes due to data limitation can corrupt model accuracy.

M-SDMs aim for structural realism by including many ecological processes. From their dynamic interplay, key model output (e.g. species geographic distributions) emerges. The gain in structural realism should enable reliable projections across a wider range of abiotic and biotic conditions, even beyond the particular environmental conditions used for model parameterization (Evans et al., 2013) and for different assumptions on species traits, interactions, and evolution. The scheme (Fig. 3) illustrates that projections made by M-SDMs can reach the true value of a target variable, such as range shift, if relevant abiotic and biotic factors are included (Section 3.1). Yet, the scheme also visualizes the large uncertainty in the output if relevant processes are not known or cannot be sufficiently parameterized from available knowledge (Section 3.2). Even without knowledge gaps the inherent uncertainty due to the complexity in dynamics (Section 3.3) remains a source of projection uncertainty.

\subsection{A protocol to enhance projection reliability}

Currently, species distributions cannot be reliably projected for many species, mainly due to missing detailed ecological knowledge. Yet, a joint effort of modelling and empirical research can improve the situation. We describe a protocol to improve projection reliability of future species distributions by systematically identifying and reducing currently limiting knowledge gaps.

Step (1) Collect all relevant knowledge that might inform projections of current and future species distributions (e.g. knowledge on geographic distributions, environmental change and ecological response processes). In order to avoid missing any potentially relevant information, we suggest that the initial conceptual step of model building is guided by theory and filtered through expert knowledge and evidence (see also Gallien et al., 2010). Theory provides a generic framework that includes all generally potentially relevant processes (Section 2 ) and process implementations. This set of general ecological principles must be enhanced and filtered by system specific, sometimes non-codified anecdotal expert knowledge (Topping et al., 2015). Critically applied, system-specific knowledge and evidence quickly constrains the vast framework to a model structure that is specific to the species and communities investigated. Remaining uncertainty about model structure has to be considered by alternative model implementations (e.g. Smith et al., 2008).

Step (2) Parameterize all relevant processes. In the best case, the model can be informed by appropriately resolved data. In direct parameterization, the models can be parameterized from detailed ecological process information. Calibrations (e.g. inverse modelling (Hartig et al., 2012; Marion et al., 2012; Van der Vaart et al., 2015) or related pattern-oriented modelling (Grimm and Railsback, 2012; Wiegand et al., 2003)) facilitate implementation of largescale information (e.g. by searching for the model that best fits the data). In this way, different types of information at different scales can be applied to parameterize the model (Schurr et al., 2012). Yet, in many cases, data are missing, and we have to rely on approximations (e.g. aggregated information or information from ecologically similar species). Different sources of evidence, but also theory might provide guesses on missing process parameters.

Step (3) Assess, partition and try to quantify the consequences of various sources of uncertainty for model projections. Standard methods for analyzing complex simulation models (Meyer et al., 2009; Refsgaard et al., 2007) include: (1) Assessment of uncertainties revealed in model calibration (step 2) or uncertainty analysis of the emerging model 
outcome distribution. (2) Model selection, model averaging or structural and parameter sensitivity analysis (Saltelli et al., 2000) to reveal the importance of processes and process implementations. If alternative process implementations or parameter values do not relevantly affect model projections, this complexity can be omitted from the model. If processes affect model projections strongly but cannot be appropriately parameterized, it is worth gathering additional information on these processes (e.g. from empirical research) to improve projection reliability (see step 4). (3) Model validation (or 'model output corroboration'; see Augusiak et al., 2014) assesses the ability of a model to reliably project independent data (i.e. data to which it was not calibrated). Reliable projection of independent data (for example in hindcast) enhances trust that the model also reliably projects future patterns. Unfortunately, statistically independent data might not be available (Mouquet et al., 2015). (4) Scenario analysis (e.g. Peterson et al., 2003) helps characterizing the consequences of plausible but uncertain future developments. For example comparing range projections with different underlying climate change scenarios (Moss et al., 2010; Spangenberg et al., 2012) provides insight in the impact of potential societal and climatic developments. For further approaches to handle, reduce or cope with uncertainty, see a review by Haila et al. (2014).

Step (4) Implement an iterative loop of model improvement alternating with empirical data acquisition. Steps 2 and 3 reveal knowledge gaps that critically affect projection reliability. These relevant knowledge gaps should predominantly be tackled by empirical research, because the respective information has high potential to improve projection reliability. As such, the protocol suggests mutual stipulation of modelling and empirical research to overcome limiting knowledge gaps.

Step (5) Communicate. Thorough communication is essential to allow for evaluation and interpretation of model projection reliability (Gregr and Chan, 2015) and to avoid unjustified generalization or application (Mouquet et al., 2015). Following protocols from ecological risk assessment (Pe'er et al., 2013; Schmolke et al., 2010), studies on future species projections require detailed documentation of (1) the model (following sophisticated protocols such as the ODD-protocol; Grimm et al., 2006), (2) alternative model implementations, (3) rationales for modelling decisions (e.g. expert information, data, or theory), (4) available information and sources of uncertainty, (5) projection uncertainty and (6) interpretation.

This protocol follows common approaches from systems analysis that have been advocated to structure modelling of ecological systems (Jopp et al., 2011). System analysis and other techniques to construct complex ecological models (e.g. Grimm and Railsback, 2005) are applied to determine relevant processes and their interactions, define model and process structure, identify parameters and knowledge gaps. New to the suggested protocol is that it particularly aims at enhancing projection reliability. The protocol requires not only to improve understanding of the system's behaviour under known conditions, but also to provide a comprehensive picture of possible future outcomes. Comprehensive means exploration of possible outcomes is supported by incorporating all relevant knowledge (step 1) as well as implementing (step 2) and evaluating (step 3 ) alternative models that conform to current knowledge. The protocol goes beyond usual parsimony-based criteria of model building (as recently requested by Topping et al., 2015), and instead defines a framework to even take into account evaluation of consequences of plausible and potentially relevant processes.

\subsection{The pros and cons of applying this protocol}

The protocol structures compilation of knowledge that is required for reliable projections. Stepwise, required, available, and desired knowledge is identified and implemented in the projection model. This procedure provides transparency of the knowledge base that underlies the model and model projections (see also the system analysis approach in Jopp et al., 2011). In this sense, the protocol implements 'evaludation' (Augusiak et al., 2014) to allow for the assessment of projection quality.

The protocol reveals consequences of lacking or unreliable information. Missing or erroneous knowledge about implemented processes and related parameters translates into projection uncertainty. This model-dependent uncertainty comprises the consequences of current knowledge gaps (Section 3.2) and inherent sources of uncertainty (Section 3.3).

The information obtained on the relevance of knowledge gaps will then guide efficient allocation of empirical efforts. In the joint empirical and modelling effort, research is focused on improving the knowledge base for influential but currently under-informed ecological processes. The additional information will improve projection reliability.

Critical to the protocol (steps 1-3) is the selection of relevant processes that should be included in projection models. Process selection is difficult, because usually there is insufficient knowledge on process relevance. Different strategies of process selection have been suggested and are commonly applied:

Firstly, it is suggested to rely on available data. Gallien et al. (2010) suggests that projection reliability for species invasion improves if implemented processes are selected according to the availability of data for their parameterization. Secondly, parsimony is a common criterion to identify relevant processes. The objective is to reduce the model to the smallest subset of processes and factors that efficiently contribute to explain variance in the data (Borcard et al., 2011). Thirdly, ecologically plausible processes are in principal relevant. The processes are parameterized from the available data as good as possible, and consequences of knowledge gaps are evaluated.

These strategies of process selection have their advantages and disadvantages. The first and second strategies achieve well parameterized models that might lack potentially relevant processes (cf. Topping et al., 2015). Potentially relevant processes might be ignored due to the lack of data to parameterize them, or they might be ruled out by statistical model selection due to lack of empirical evidence for process relevance. Statistical model selection can falsely underestimate process relevance, if for example a biotic response has not been investigated along an environmental gradient that is likely realized in the future.

The third strategy may lead to complex models that often cannot be sufficiently parameterized. It is likely that the emergent model outcome distribution will include the true value (see Fig. 3). But, due to the high uncertainty, this is of little practical use. Therefore, complex dynamic models have been criticized. Two main criticisms are brought forward. Firstly, complex models are hard to understand and their dynamics are not easily tractable (e.g. Levins, 1966). In particular, erroneous specification of complex models could strongly corrupt projection reliability. Secondly, they are potentially over-fitting and hard to parameterize, because their processes can internally be highly correlated (e.g. Hartig et al., 2014). It might be impossible to resolve these correlations with the presently available patterns and data (Dormann et al., 2012).

The above described strategies for process selection are extremes. In order to practically build well-suited projection 
models that balance model complexity against available information (Johnson and Omland, 2004; Thuiller et al., 2013), the strategies should be consciously modified and combined.

Nevertheless, we reiterate that, even from the best constructed models, reliable projections of species range shifts cannot be expected in the current situation of severe knowledge gaps for many species. Overly optimistic assessment of model reliability in the context of decision making is risky, and shortcomings of projections must be highlighted (e.g. Gould et al., 2014) and communicated. In the protocol, the purpose of models is reliable projection. If projection reliability is weak, the models help revealing consequences of knowledge gaps (concerning model structure and parameterization) and of inherent uncertainty due to complex (stochastic nonlinear) community dynamics. In this way, models support identifying the responsible sources of uncertainty.

To be fit for purpose, models must include the set of processes that potentially relevantly influence the specific species and community responses to environmental change (Section 2), as well as the accompanying uncertainty (Section 3). This set is easiest to be implemented in M-SDMs. The process-based modelling framework allows important flexibility, which is difficult to achieve in a correlative approach. Ecological processes are the building blocks of M-SDMs. Processes can easily be included or modified. Further, mechanistic models can be parameterized from different types of data across different scales (Schurr et al., 2012).

We agree that projection models applied in the framework of the protocol are complex. We advocate for accepting this necessary complexity (Topping et al., 2015) and resulting uncertainty (c.f. Pe'er et al., 2014). From this complexity and uncertainty the limits to projection reliability emerge.

Yet, ultimately the protocol aims at providing reliable projections of future species and community ranges. In order to improve projection reliability, which currently is limited by a lack of knowledge, we advocate for an efficient enhancement of relevant knowledge (c.f. Schurr et al., 2012). The protocol helps to identify available knowledge, and to fill critical knowledge gaps in joint and targeted empirical and modelling research efforts.

\section{Conclusions}

Next generation species distribution models can and should take into account not only the (abiotic) landscape change correlated to the realized species niches, but explicitly the (biotic) population and community processes that are involved in the response to the abiotic change (c.f. Bocedi et al., 2014; Evans et al., 2013; Kearney and Porter, 2009; Snell et al., 2014). At a first glance, the large amount of information required to parameterize the complex mechanistic species distribution models might appear to be a drawback. However, this 'data hunger' actually reflects the knowledge that is necessary to reliably project future species and community distributions.

We suggest a protocol to reliably project species distributions in a joint modelling and empirical research effort. Models guide empirical research to target critical knowledge gaps that currently limit projection reliability. The targeted research will quickly improve reliability of species and community range projections.

\section{Acknowledgements}

This paper is based on the findings and the follow up discussions of a workshop at the INTECOL 2013 conference in London called 'Species interactions and survival in dynamic landscapes: How predictable is the future?' organized by Karin Johst, Alexander Singer and Justin MJ Travis. We thank all participants for the interesting discussions. The work was further facilitated by the working group rangeShifter supported by sDiv, the Synthesis Centre for
Biodiversity Sciences within the German Centre for Integrative Biodiversity Research (iDiv) Halle-Jena-Leipzig (DFG FZT 118). AGG was funded by a CONICYT-PAI (number 82130046) grant. GP was funded by the FP7 projects SCALES (contract 226852) and EU BON (308454)

\section{References}

Albert, C.H., Grassein, F., Schurr, F.M., Vieilledent, G., Violle, C., 2011. When and how should intraspecific variability be considered in trait-based plant ecology? Perspect. Plant Ecol. Evol. Syst. 13, 217-225, http://dx.doi.org/10.1016/j.ppees. 2011.04.003.

Anderson, C.B., Vanessa Lencinas, M., Wallem, P.K., Valenzuela, A.E.J., Simanonok, M.P., Martínez Pastur, G., 2014. Engineering by an invasive species alters landscape-level ecosystem function, but does not affect biodiversity in freshwater systems. Divers. Distrib. 20, 214-222, http://dx.doi.org/10.1111/ddi.12147.

Atkins, K.E., Travis, J.M.J., 2010. Local adaptation and the evolution of species' ranges under climate change. J. Theor. Biol. 266, 449-457, http://dx.doi.org/10.1016/j. jtbi.2010.07.014.

Augusiak, J., Van den Brink, P.J., Grimm, V., 2014. Merging validation and evaluation of ecological models to "evaludation": a review of terminology and a practical approach. Ecol. Modell. 280,117-128, http://dx.doi.org/10.1016/j.ecolmodel. 2013.11.009.

Barabás, G., Pásztor, L., Meszéna, G., Ostling, A., 2014. Sensitivity analysis of coexistence in ecological communities: theory and application. Ecol. Lett. 17, 1479-1494, http://dx.doi.org/10.1111/ele.12350.

Bartomeus, I., Ascher, J.S., Wagner, D., Danforth, B.N., Colla, S., Kornbluth, S., Winfree, R., 2011. Climate-associated phenological advances in bee pollinators and beepollinated plants. Proc. Natl. Acad. Sci. U. S. A. 108, 20645-20649, http://dx.doi. org/10.1073/pnas.1115559108.

Bastolla, U., Fortuna, M.A., Pascual-Garcia, A., Ferrera, A., Luque, B., Bascompte, J., 2009. The architecture of mutualistic networks minimizes competition and increases biodiversity. Nature 458, 1018-1020.

Bellard, C., Bertelsmeier, C., Leadley, P., Thuiller, W., Courchamp, F., 2012. Impacts of climate change on the future of biodiversity. Ecol. Lett. 15, 365-377, http:// dx.doi.org/10.1111/j.1461-0248.2011.01736.x.

Best, A.S., Johst, K., Münkemüller, T., Travis, J.M.J., 2007. Which species will successfully track climate change? The influence of intraspecific competition and density dependent dispersal on range shifting dynamics. Oikos 116, 1531-1539.

Binzer, A., Brose, U., Curtsdotter, A., Eklöf, A., Rall, B.C., Riede, J.O., de Castro, F., 2011. The susceptibility of species to extinctions in model communities. Basic Appl. Ecol. 12, 590-599, http://dx.doi.org/10.1016/j.baae.2011.09.002.

Blois, J.L., Zarnetske, P.L., Fitzpatrick, M.C., Finnegan, S., 2013. Climate change and the past, present, and future of biotic interactions. Science 341, 499-504, http:// dx.doi.org/10.1126/science.1237184.

Bocedi, G., Atkins, K.E., Liao, J., Henry, R.C., Travis, J.M.J., Hellmann, J.J., 2013. Effects of local adaptation and interspecific competition on species' responses to climate change. Ann. N. Y. Acad. Sci. 1297, 83-97, http://dx.doi.org/10.1111/nyas.12211.

Bocedi, G., Palmer, S.C.F., Pe'er, G., Heikkinen, R.K., Matsinos, Y.G., Watts, K., Travis, J.M.J., 2014. RangeShifter: a platform for modelling spatial eco-evolutionary dynamics and species' responses to environmental changes. Methods Ecol. Evol. 5, 388-396, http://dx.doi.org/10.1111/2041-210X. 12162

Bonan, G.B., 2008. Forests and climate change: forcings, feedbacks, and the climate benefits of forests. Science 320, 1444-1449, http://dx.doi.org/10.1126/science. 1155121.

Borcard, D., Gillet, F., Legendre, P., 2011. Numerical Ecology with R Media. Springer, New York.

Boulangeat, I., Gravel, D., Thuiller, W., 2012. Accounting for dispersal and biotic interactions to disentangle the drivers of species distributions and their abundances Ecol. Lett. 15, 584-593.

Bourne, E.C., Bocedi, G., Travis, J.M.J., Pakeman, R.J., Brooker, R.W., Schiffers, K., 2014. Between migration load and evolutionary rescue: dispersal, adaptation and the response of spatially structured populations to environmental change. Proc. $R$. Soc. B: Biol. Sci. 281, 20132795, http://dx.doi.org/10.1098/rspb.2013.2795.

Brooker, R.W., Travis, J.M.J., Clark, E.J., Dytham, C., 2007. Modelling species' range shifts in a changing climate: the impacts of biotic interactions, dispersal distance and the rate of climate change. J. Theor. Biol. 245, 59-65.

Buckley, L.B., Urban, M.C., Angilletta, M.J., Crozier, L.G., Rissler, L.J., Sears, M.W., 2010 Can mechanism inform species' distribution models? Ecol. Lett. 13, 1041-1054, http://dx.doi.org/10.1111/j.1461-0248.2010.01479.x.

Burton, O.J., Phillips, B.L., Travis, J.M.J., 2010. Trade-offs and the evolution of lifehistories during range expansion. Ecol. Lett. 13, 1210-1220, http://dx.doi.org/ 10.1111/j.1461-0248.2010.01505.x.

Buse, J., Griebeler, E.M., 2011. Incorporating classified dispersal assumptions in predictive distribution models - a case study with grasshoppers and bush-crickets. Ecol. Modell. 222, 2130-2141.

Chen, I.-C., Hill, J.K., Ohlemüller, R., Roy, D.B., Thomas, C.D., 2011. Rapid range shifts of species associated with high levels of climate warming. Science 333, 1024-1026, http://dx.doi.org/10.1126/science.1206432.

Chesson, P., 2000. Mechanisms of maintenance of species diversity. Annu. Rev. Ecol Syst. 31, 343-366, http://dx.doi.org/10.1146/annurev.ecolsys.31.1.343.

Chuine, I., Beaubien, E.G., 2001. Phenology is a major determinant of tree species range. Ecol. Lett. 4, 500-510, http://dx.doi.org/10.1046/j.1461-0248. 2001.00261.x 
Cobben, M.M.P., Verboom, J., Opdam, P.F.M., Hoekstra, R.F., Jochem, R., Arens, P., Smulders, M.J.M., 2011. Projected climate change causes loss and redistribution of genetic diversity in a model metapopulation of a medium-good disperser. Ecography 34,920-932, http://dx.doi.org/10.1111/j.1600-0587.2011.06713.x.

Cobben, M.M.P., Verboom, J., Opdam, P.F.M., Hoekstra, R.F., Jochem, R., Smulders, M.J.M., 2012. Wrong place, wrong time: climate change-induced range shift across fragmented habitat causes maladaptation and declined population size in a modelled bird species. Glob. Change Biol. 18, 2419-2428, http://dx.doi.org/ 10.1111/j.1365-2486.2012.02711.x.

Davis, M.B., 1981. Quaternary history and the stability of forest communities. In: Forest Succession. Springer, pp. 132-153.

De Cáceres, M., Brotons, L., 2012. Calibration of hybrid species distribution models: the value of general-purpose vs. targeted monitoring data. Divers. Distrib. 18, 977-989, http://dx.doi.org/10.1111/j.1472-4642.2012.00899.x.

DeAngelis, D.L., Mooij, W.M., 2005. Individual-based modeling of ecological and evolutionary processes. Annu. Rev. Ecol. Evol. Syst. 36, 147-168, http://dx.doi.org/ 10.1146/annurev.ecolsys.36.102003.152644.

Doak, D.F., Estes, J.A., Halpern, B.S., Jacob, U., Lindberg, D.R., Lovvorn, J., Monson, D.H., Tinker, M.T., Williams, T.M., Wootton, J.T., Carroll, I., Emmerson, M., Micheli, F., Novak, M., 2008. Understanding and predicting ecological dynamics: are major surprises inevitable? Ecology 89, 952-961.

Donalson, D.D., Nisbet, R.M., 1999. Population dynamics and spatial scale: effects of system size on population persistence. Ecology 80, 2492-2507.

Dormann, C.F., 2007. Promising the future? Global change projections of species distributions. Basic Appl. Ecol. 8, 387-397, http://dx.doi.org/10.1016/j.baae.2006. 11.001.

Dormann, C.F., Schymanski, S.J., Cabral, J., Chuine, I., Graham, C., Hartig, F., Kearney, M., Morin, X., Römermann, C., Schröder, B., Singer, A., 2012. Correlation and process in species distribution models: bridging a dichotomy. J. Biogeogr. 39, 2119-2131, http://dx.doi.org/10.1111/j.1365-2699.2011.02659.x.

Dullinger, S., Gattringer, A., Thuiller, W., Moser, D., Zimmermann, N.E., Guisan, A Willner, W., Plutzar, C., Leitner, M., Mang, T., Caccianiga, M., Dirnböck, T., Ertl, S., Fischer, A., Lenoir, J., Svenning, J.-C., Psomas, A., Schmatz, D.R., Silc, U., Vittoz, P., Hülber, K., 2012. Extinction debt of high-mountain plants under twentyfirst-century climate change. Nat. Clim. Change 2, 619-622, http://dx.doi.org/ 10.1038/nclimate1514.

Dunne, J.A., Williams, R.J., Martinez, N.D., 2002. Network structure and biodiversity loss in food webs: robustness increases with connectance. Ecol. Lett. 5, 558-567. http://dx.doi.org/10.1046/j.1461-0248.2002.00354.x.

Engler, R., Guisan, A., 2009. MigClim: predicting plant distribution and dispersal in a changing climate. Divers. Distrib. 15, 590-601.

Evans, M.R., Bithell, M., Cornell, S.J., Dall, S.R.X., Díaz, S., Emmott, S., Ernande, B., Grimm, V., Hodgson, D.J., Lewis, S.L., Mace, G.M., Morecroft, M., Moustakas, A., Murphy, E., Newbold, T., Norris, K.J., Petchey, O., Smith, M., Travis, J.M.J., Benton, T.G., 2013. Predictive systems ecology. Proc. Biol. Sci. 280, 20131452, http://dx. doi.org/10.1098/rspb.2013.1452.

Fordham, D.A., Mellin, C., Russell, B.D., Akçakaya, R.H., Bradshaw, C.J.A, AielloLammens, M.E., Caley, J.M., Connell, S.D., Mayfield, S., Shepherd, S.A., Brook, B.W., 2013. Population dynamics can be more important than physiological limits for determining range shifts under climate change. Glob. Change Biol. 19, 3224-3237, http://dx.doi.org/10.1111/gcb.12289.

Fowler, M.S., Ruokolainen, L., 2013. Confounding environmental colour and distribution shape leads to underestimation of population extinction risk. PLOS ONE 8, e55855, http://dx.doi.org/10.1371/journal.pone.0055855.

Fukami, T., Nakajima, M., 2011. Community assembly: alternative stable states or alternative transient states? Ecol. Lett. 14, 973-984, http://dx.doi.org/10.1111/ j.1461-0248.2011.01663.x.

Gallien, L., Münkemüller, T., Albert, C.H., Boulangeat, I., Thuiller, W., 2010. Predicting potential distributions of invasive species: where to go from here? Divers. Distrib. 16, 331-342.

Geange, S.W., Stier, A.C., 2009. Order of arrival affects competition in two reef fishes. Ecology 90, 2868-2878.

Gilman, S.E., Urban, M.C., Tewksbury, J., Gilchrist, G.W., Holt, R.D., 2010. A framework for community interactions under climate change. Trends Ecol. Evol. 25, 325-331, http://dx.doi.org/10.1016/j.tree.2010.03.002.

Gould, S.F., Beeton, N.J., Harris, R.M.B., Hutchinson, M.F., Lechner, A.M., Porfirio, L.L., Mackey, B.G., 2014. A tool for simulating and communicating uncertainty when modelling species distributions under future climates. Ecol. Evol. 4, 4798-4811, http://dx.doi.org/10.1002/ece3.1319.

Greenman, J.V., Benton, T.G., 2003. The amplification of environmental noise in population models: causes and consequences. Am. Nat. 161, 225-239, http://dx.doi. org/10.1086/345784.

Gregr, E.J., Chan, K.M.A., 2015. Leaps of faith: how implicit assumptions compromise the utility of ecosystem models for decision-making. Bioscience $65,43-54$, http://dx.doi.org/10.1093/biosci/biu185.

Grimm, V., Railsback, S.F., 2005. Individual-Based Modeling and Ecology. Princeton University Press.

Grimm, V., Railsback, S.F., 2012. Pattern-oriented modelling: a "multi-scope" for predictive systems ecology. Philos. Trans. R. Soc. B: Biol. Sci. 367, 298-310, http:// dx.doi.org/10.1098/rstb.2011.0180.

Grimm, V., Berger, U., Bastiansen, F., Eliassen, S., Ginot, V., Giske, J., Goss-Custard, J., Grand, T., Heinz, S.K., Huse, G., Huth, A., Jepsen, J.U., Jørgensen, C., Mooij, W.M., Müller, B., Pe'er, G., Piou, C., Railsback, S.F., Robbins, A.M., Robbins, M.M., Rossmanith, E., Rüger, N., Strand, E., Souissi, S., Stillman, R.A., Vabø, R., Visser, U., DeAngelis, D.L., 2006. A standard protocol for describing individual-based and agent-based models. Ecol. Modell. 198, 115-126, http://dx.doi.org/10.1016/ j.ecolmodel.2006.04.023.

Guisan, A., Thuiller, W., 2005. Predicting species distribution: offering more than simple habitat models. Ecol. Lett. 8, 993-1009, http://dx.doi.org/10.1111/j.1461 0248.2005.00792.x.

Guisan, A., Zimmermann, N.E., 2000. Predictive habitat distribution models in ecology. Ecol. Modell. 135, 147-186, http://dx.doi.org/10.1016/S03043800(00)00354-9.

Guisan, A., Lehmann, A., Ferrier, S., Austin, M., Overton, J.M.C., Aspinall, R., Hastie T., 2006. Making better biogeographical predictions of species' distributions. J. Appl. Ecol. 43, 386-392.

Haila, Y., Henle, K., Apostolopoulou, E., Cent, J., Framstad, E., Goerg, C., Jax, K., Klenke R., Magnuson, W., Matsinos, Y., Mueller, B., Paloniemi, R., Pantis, J., Rauschmayer, F., Ring, I., Settele, J., Simila, J., Touloumis, K., Tzanopoulos, J., Pe'er, G., 2014 Confronting and coping with uncertainty in biodiversity research and praxis. Nat. Conserv. 8, 45-75, http://dx.doi.org/10.3897/natureconservation.8.5942.

Hartig, F., Dyke, J., Hickler, T., Higgins, S.I., O’Hara, R.B., Scheiter, S., Huth, A., 2012 Connecting dynamic vegetation models to data - an inverse perspective. J. Biogeogr. 39, 2240-2252.

Hartig, F., Dislich, C., Wiegand, T., Huth, A., 2014. Technical note: approximate Bayesian parameterization of a process-based tropical forest model. Biogeosciences 11, 1261-1272, http://dx.doi.org/10.5194/bg-11-1261-2014.

Hastings, A., 2004. Transients: the key to long-term ecological understanding? Trends Ecol. Evol. 19, 39-45, http://dx.doi.org/10.1016/j.tree.2003.09.007.

Hegland, S.J., Nielsen, A., Lázaro, A., Bjerknes, A.L., Totland, Ø., 2009. How does climate warming affect plant-pollinator interactions? Ecol. Lett., http://dx.doi.org/ 10.1111/j.1461-0248.2008.01269.x.

Hendry, A.P., Nosil, P., Rieseberg, L.H., 2007. The speed of ecological speciation. Funct Ecol. 21, 455-464, http://dx.doi.org/10.1111/j.1365-2435.2006.01240.x.

Hickling, R., Roy, D.B., Hill, J.K., Fox, R., Thomas, C.D., 2006. The distributions of a wide range of taxonomic groups are expanding polewards. Glob. Change Biol. 12, 450-455, http://dx.doi.org/10.1111/j.1365-2486.2006.01116.x.

Higgins, S.I., Clark, J.S., Nathan, R., Hovestadt, T., Schurr, F., Fragoso, J.M.V., Aguiar, M.R., Ribbens, E., Lavorel, S., 2003. Forecasting plant migration rates: managing uncertainty for risk assessment. J. Ecol. 91, 341-347, http://dx.doi.org/10.1046/ j.1365-2745.2003.00781.x.

Higgins, S.I., O’Hara, R.B., Römermann, C., 2012. A niche for biology in species distribution models. J. Biogeogr. 39, 2091-2095, http://dx.doi.org/10.1111/jbi.12029.

Hill, J.K., Griffiths, H.M., Thomas, C.D., 2011. Climate change and evolutionary adaptations at species' range margins. Annu. Rev. Entomol. 56, 143-159, http://dx. doi.org/10.1146/annurev-ento-120709-144746.

Hobbs, R.J., Higgs, E., Harris, J.A., 2009. Novel ecosystems: implications for conservation and restoration. Trends Ecol. Evol. 24, 599-605, http://dx.doi.org/10.1016 j.tree.05.012.2009.

Johnson, J.B., Omland, K.S., 2004. Model selection in ecology and evolution. Trends Ecol. Evol. 19, 101-108, http://dx.doi.org/10.1016/j.tree.2003.10.013.

Johst, K., Drechsler, M., 2003. Are spatially correlated or uncorrelated disturbance regimes better for the survival of species? Oikos 103, 449-456, http://dx.doi. org/10.1034/j.1600-0706.2003.12770.x.

Johst, K., Wissel, C., 1997. Extinction risk in a temporally correlated fluctuating environment. Theor. Popul. Biol. 52, 91-100.

Johst, K., Lima, M., Berryman, A.A., 2013. Scaling up: how do exogenous fluctuations in individual-based resource competition models re-emerge in aggregated stochastic population models? Popul. Ecol. 55, 173-182, http://dx.doi.org/10. 1007/s10144-012-2.0345.

Jones, K.E., Bielby, J., Cardillo, M., Fritz, S.A., O’Dell, J., Orme, C.D.L., Safi, K., Sechrest, W., Boakes, E.H., Carbone, C., Connolly, C., Cutts, M.J., Foster, J.K., Grenyer, R. Habib, M., Plaster, C.A., Price, S.A., Rigby, E.A., Rist, J., Teacher, A., BinindaEmonds, O.R.P., Gittleman, J.L., Mace, G.M., Purvis, A., 2009. PanTHERIA: a species-level database of life history, ecology, and geography of extant and recently extinct mammals. Ecology 90, 2648, http://dx.doi.org/10.1890/08 1494.1.

Jopp, F., Jørgensen, S.E., Trexler, M., Reuter, H., DeAngelis, D.L., Breckling, B., 2011. Modelling Complex Ecological Dynamics: An Introduction into Ecological Modelling for Students Teachers \& Scientists. Springer Science \& Business Media.

Jump, A.S., Huang, T.J., Chou, C.H., 2012. Rapid altitudinal migration of mountain plants in Taiwan and its implications for high altitude biodiversity. Ecography 35, 204-210, http://dx.doi.org/10.1111/j.1600-0587.2011.06984.x.

Kattge, J., Díaz, S., Lavorel, S., Prentice, I.C., Leadley, P., Bönisch, G., Garnier, E., Westoby, M., Reich, P.B., Wright, I.J., Cornelissen, J.H.C., Violle, C., Harrison, S.P., Van Bodegom, P.M., Reichstein, M., Enquist, B.J., Soudzilovskaia, N.A., Ackerly, D.D., Anand, M., Atkin, O., Bahn, M., Baker, T.R., Baldocchi, D., Bekker, R., Blanco, C.C., Blonder, B., Bond, W.J., Bradstock, R., Bunker, D.E., Casanoves, F., Cavender-Bares, J., Chambers, J.Q., Chapin, F.S., Chave, J., Coomes, D., Cornwell, W.K., Craine, J.M. Dobrin, B.H., Duarte, L., Durka, W., Elser, J., Esser, G., Estiarte, M., Fagan, W.F. Fang, J., Fernández-Méndez, F., Fidelis, a., Finegan, B., Flores, O., Ford, H., Frank D., Freschet, G.T., Fyllas, N.M., Gallagher, R.V., Green, W.A., Gutierrez, A.G., Hickler, T., Higgins, S.I., Hodgson, J.G., Jalili, A., Jansen, S., Joly, C.A., Kerkhoff, A.J., Kirkup, D., Kitajima, K., Kleyer, M., Klotz, S., Knops, J.M.H., Kramer, K., Kühn, I., Kurokawa, H., Laughlin, D., Lee, T.D., Leishman, M., Lens, F., Lenz, T., Lewis, S.L., Lloyd, J., Llusià, J., Louault, F., Ma, S., Mahecha, M.D., Manning, P., Massad, T., Medlyn, B.E., Messier, J., Moles, A.T., Müller, S.C., Nadrowski, K., Naeem, S. Niinemets, Ü., Nöllert, S., Nüske, A., Ogaya, R., Oleksyn, J., Onipchenko, V.G. Onoda, Y., Ordoñez, J., Overbeck, G., Ozinga, W.A., Patiño, S., Paula, S., Pausas, J.G., Peñuelas, J., Phillips, O.L., Pillar, V., Poorter, H., Poorter, L., Poschlod, P., Prinzing, A., Proulx, R., Rammig, A., Reinsch, S., Reu, B., Sack, L., Salgado-Negret, 
B. Sardans, J., Shiodera, S., Shipley, B., Siefert, A., Sosinski, E., Soussana, J.F., Swaine, E., Swenson, N., Thompson, K., Thornton, P., Waldram, M., Weiher, E., White, M., White, S., Wright, S.J., Yguel, B., Zaehle, S., Zanne, A.E., Wirth, C., 2011. TRY - a global database of plant traits. Glob. Change Biol. 17, 2905-2935, http:// dx.doi.org/10.1111/j.1365-2486.2011.02451.x.

Kearney, M., Porter, W., 2009. Mechanistic niche modelling: combining physiological and spatial data to predict species' ranges. Ecol. Lett. 12, 334-350, http://dx.doi. $\operatorname{org} / 10.1111 / \mathrm{j} .1461-0248.2008 .01277 . x$

Kearney, M., Phillips, B.L., Tracy, C.R., Christian, K.A., Betts, G., Porter, W.P., 2008 Modelling species distributions without using species distributions: the cane toad in Australia under current and future climates. Ecography 31, 423-434, http://dx.doi.org/10.1111/j.0906-7590.2008.05457.x.

Keil, P., Schweiger, O., Kühn, I., Kunin, W.E., Kuussaari, M., Settele, J., Henle, K., Brotons, L., Pe'er, G., Lengyel, S., Moustakas, A., Steinicke, H., Storch, D., 2012. Patterns of beta diversity in Europe: the role of climate, land cover and distance across scales. J. Biogeogr. 39, 1473-1486, http://dx.doi.org/10.1111/j. 1365-2699.2012.02701.x.

Kissling, W.D., Field, R., Korntheuer, H., Heyder, U., Böhning-Gaese, K., 2010. Woody plants and the prediction of climate-change impacts on bird diversity. Philos. Trans. R. Soc. Lond. B: Biol. Sci. 365, 2035-2045, http://dx.doi.org/10.1098/rstb. 2010.0008.

Kissling, W.D., Dormann, C.F., Groeneveld, J., Hickler, T., Kühn, I., McInerny, G.J., Montoya, J.M., Römermann, C., Schiffers, K., Schurr, F.M., Singer, A., Svenning J.-C., Zimmermann, N.E., O'Hara, R.B., 2012. Towards novel approaches to modelling biotic interactions in multispecies assemblages at large spatial extents. J. Biogeogr. 39, 2163-2178, http://dx.doi.org/10.1111/j.1365-2699.2011.02663.x.

Kopp, M., Matuszewski, S., 2014. Rapid evolution of quantitative traits: theoretica perspectives. Evol. Appl. 7, 169-191, http://dx.doi.org/10.1111/eva.12127.

Lavorel, S., Garnier, E., 2002. Predicting changes in community composition and ecosystem functioning from plant traits: revisiting the Holy Grail. Funct. Ecol. $16,545-556$.

Laws, A.N., Joern, A., 2013. Predator-prey interactions in a grassland food chain vary with temperature and food quality. Oikos 122, 977-986, http://dx.doi.org/10. 1111/j.1600-0706.2012.20419.x.

Leadley, P.W., Krug, C.B., Alkemade, R., Pereira, H.M., Sumaila, U.R., Walpole, M., Mar ques, A., Newbold, T., Teh, L.S., van Kolck, J., Bellard, C., Januchowski-Hartley, S.R. Mumby, P.J., 2014. Progress Towards the Aichi Biodiversity Targets: An Assessment of Biodiversity Trends, Policy Scenarios and Key Actions. Technical Series. Montreal, Canada.

Lenoir, J., Gégout, J.C., Marquet, P.A., de Ruffray, P., Brisse, H., 2008. A significan upward shift in plant species optimum elevation during the 20th century. Science 320,1768-1771, http://dx.doi.org/10.1126/science.1156831.

Levins, R., 1966. The strategy of model building in population biology. Am. Sci. 54 $421-431$

Liess, M., Foit, K., 2010. Intraspecific competition delays recovery of population structure. Aquat. Toxicol. 97, 15-22, http://dx.doi.org/10.1016/j.aquatox.2009. 11.018

Liess, M., Schäfer, R.B., Schriever, C.A., 2008. The footprint of pesticide stress in communities - species traits reveal community effects of toxicants. Sci. Total Environ. 406, 484-490, http://dx.doi.org/10.1016/j.scitotenv.2008.05.054.

Lischke, H., Zimmermann, N.E., Bolliger, J., Rickebusch, S., Löffler, T.J., 2006. TreeMig: a forest-landscape model for simulating spatio-temporal patterns from stand to landscape scale. Ecol. Modell. 199, 409-420.

Loreau, M., 2010. Linking biodiversity and ecosystems: towards a unifying ecologica theory. Philos. Trans. R. Soc. Lond. B: Biol. Sci. 365, 49-60, http://dx.doi.org/10. 1098/rstb.2009.0155.

Lurgi, M., Brook, B.W., Saltré, F., Fordham, D.A., 2015. Modelling range dynamics under global change: which framework and why? Methods Ecol. Evol. 6 247-256, http://dx.doi.org/10.1111/2041-210X. 12315.

Marion, G., McInerny, G.J., Pagel, J., Catterall, S., Cook, A.R., Hartig, F., O'Hara, R.B., 2012. Parameter and uncertainty estimation for process-oriented population and distribution models: data, statistics and the niche. J. Biogeogr. 39 2225-2239, http://dx.doi.org/10.1111/j.1365-2699.2012.02772.x.

Martin, B.T., Nisbet, R.M., Pike, A., Michel, C.J., Danner, E.M., 2015. Sport science for salmon and other species: ecological consequences of metabolic power constraints. Ecol. Lett. 18, 535-544, http://dx.doi.org/10.1111/ele.12433.

Matlack, G.R., Leu, N.A., 2007. Persistence of dispersal-limited species in structured dynamic landscapes. Ecosystems 10, 1287-1298, http://dx.doi.org/10. 1007/s10021-007-9.9097.

Matthiopoulos, J., Fieberg, J., Aarts, G., Beyer, H.L., Morales, J.M., Haydon, D.T., 2015. Establishing the link between habitat selection and animal population dynamics. Ecol. Monogr. 85, 413-436, http://dx.doi.org/10.1890/14-2244.1.

Meier, E.S., Pearman, P.B., Svenning, J.C., Thuiller, W., Araujo, M.B., Guisan, A Zimmermann, N.E., 2010. Biotic and abiotic variables show little redundancy in explaining tree species distributions. Ecography 33, 1038-1048

Meier, E.S., Lischke, H., Schmatz, D.R., Zimmermann, N.E., 2012. Climate, competition and connectivity affect future migration and ranges of European trees. Glob. Ecol. Biogeogr. 21, 164-178.

Memmott, J., Craze, P.G., Waser, N.M., Price, M.V., 2007. Global warming and the disruption of plant-pollinator interactions. Ecol. Lett. 10, 710-717.

Menendez, R., Gonzalez-Megias, A., Lewis, O.T., Shaw, M.R., Thomas, C.D., 2008. Escape from natural enemies during climate-driven range expansion: a case study. Ecol. Entomol. 33, 413-421.

Meyer, K.M., Mooij, W.M., Vos, M., Hol, W.H.G., van der Putten, W.H., 2009. The power of simulating experiments. Ecol. Modell. 220, 2594-2597, http://dx.doi.org/10. 1016/j.ecolmodel.2009.06.001.
Moir, M.L., Hughes, L., Vesk, P.A., Leng, M.C., 2014. Which host-dependent insects are most prone to coextinction under changed climates? Ecol. Evol. 4, 1295-1312, http://dx.doi.org/10.1002/ece3.1021.

Moran, E.V., Hartig, F., Bell, D.M., 2016. Intraspecific trait variation across scales: implications for understanding global change responses. Glob. Change Biol. 22, 137-150, http://dx.doi.org/10.1111/gcb.13000.

Morin, X., Augspurger, C., Chuine, I., 2007. Process-based modeling of species' distributions: what limits temperate tree species' range boundaries? Ecology 88 2280-2291, http://dx.doi.org/10.1890/06-1591.1.

Morin, X., Viner, D., Chuine, I., 2008. Tree species range shifts at a continental scale: new predictive insights from a process-based model. J. Ecol. 96, 784-794, http:/ dx.doi.org/10.1111/j.1365-2745.2008.01369.x.

Moss, R.H., Edmonds, J.A., Hibbard, K.A., Manning, M.R., Rose, S.K., van Vuuren, D.P., Carter, T.R., Emori, S., Kainuma, M., Kram, T, Meehl, G.A., Mitchell, J.F.B., Nakicenovic, N., Riahi, K., Smith, S.J., Stouffer, R.J., Thomson, A.M., Weyant, J.P., Wilbanks, T.J., 2010. The next generation of scenarios for climate change research and assessment. Nature 463, 747-756, http://dx.doi.org/10.1038/nature08823.

Mouquet, N., Lagadeuc, Y., Devictor, V., Doyen, L., Duputié, A., Eveillard, D., Faure, D. Garnier, E., Gimenez, O., Huneman, P., Jabot, F., Jarne, P., Joly, D., Julliard, R., Kéfi, S., Kergoat, G.J., Lavorel, S., Le Gall, L., Meslin, L., Morand, S., Morin, X., Morlon, H., Pinay, G., Pradel, R., Schurr, F.M., Thuiller, W., Loreau, M., 2015. Predictive ecology in a changing world. J. Appl. Ecol. 52, 1293-1310, http://dx.doi.org/10. $1111 / 1365-2664.12482$.

Münkemüller, T., Reineking, B., Travis, J., Bugmann, H., Johst, K., 2009. Disappearing refuges in time and space: how environmental change threatens species coexistence. Theor. Ecol. 2, 217-227.

Münkemüller, T., Travis, M.J., Burton, O.J., Schiffers, K., Johst, K., 2011. Densityregulated population dynamics and conditional dispersal alter the fate of mutations occurring at the front of an expanding population. Heredity (Edinb) 106, 678-689, http://dx.doi.org/10.1038/hdy.2010.107.

Norberg, J., Urban, M.C., Vellend, M., Klausmeier, C.A., Loeuille, N., 2012. Ecoevolutionary responses of biodiversity to climate change. Nat. Clim. Change 2 747-751, http://dx.doi.org/10.1038/nclimate1588.

Pagel, J., Schurr, F.M., 2012. Forecasting species ranges by statistical estimation of ecological niches and spatial population dynamics. Glob. Ecol. Biogeogr. 21, 293-304, http://dx.doi.org/10.1111/j.1466-8238.2011.00663.x.

Parmesan, C., 2006. Ecological and evolutionary responses to recent climate change. Annu. Rev. Ecol. Evol. Syst. 37, 637-669, http://dx.doi.org/10.1146/annurev. ecolsys.37.091305.110100.

Parmesan, C., Yohe, G., 2003. A globally coherent fingerprint of climate change impacts across natural systems. Nature 421, 37-42.

Parmesan, C., Ryrholm, N.,Stefanescu, C., Hillk, J.K., Thomas, C.D., Descimon, H., Huntleyk, B., Kaila, L., Kullberg, J., Tammaru, T., Tennent, W.J., Thomas, J.A., Warren, M., 1999. Poleward shifts in geographical ranges of butterfly species associated with regional warming. Nature 399, 579-583, http://dx.doi.org/10.1038/21181.

Pateman, R.M. Hill, J.K., Roy, D.B., Fox, R., Thomas, C.D. 2012. Temperaturedependent alterations in host use drive rapid range expansion in a butterfly. Science 336, 1028-1030

Pe'er, G., Matsinson, Y.G., Johst, K., Franz, K.W., Turlure, C., Radchuk, V., Malinowska, A.H., Curtis, J.M.R., Naujokaitis-Lewis, I., Wintle, B.A., Henle, K., 2013. A protocol for better design, application, and communication of population viability analyses. Conserv. Biol. 27, 644-656, http://dx.doi.org/10.1111/cobi.12076.

Pe'er, G. Tsianou, M.A. Franz, K.W Matsinos, Y.G. Mazaris, A.D. Storch, D. Kopsova, L., Verboom, J., Baguette, M., Stevens, V.M., Henle, K., 2014. Toward better application of minimum area requirements in conservation planning. Biol. Conserv. 170, 92-102, http://dx.doi.org/10.1016/j.biocon.2013.12.011.

Petchey, O.L., Pontarp, M., Massie, T.M., Kéfi, S., Ozgul, A., Weilenmann, M., Palamara G.M., Altermatt, F., Matthews, B., Levine, J.M., Childs, D.Z., McGill, B.J., Schaepman, M.E., Schmid, B., Spaak, P., Beckerman, A.P., Pennekamp, F., Pearse, I.S. 2015. The ecological forecast horizon, and examples of its uses and determinants. Ecol. Lett. 18, 597-611, http://dx.doi.org/10.1111/ele.12443.

Peterson, G.D., Cumming, G.S., Carpenter, S.R., 2003. Scenario planning: a tool for conservation in an uncertain world. Conserv. Biol. 17, 358-366, http://dx.doi. org/10.1046/j.1523-1739.2003.01491.x.

Pickett, S.T., White, P.S., 1985. The Ecology of Natural Disturbance and Patch Dynamics. Academic Press.

Polce, C., Garratt, M.P., Termansen, M., Ramirez-Villegas, J., Challinor, A. J., Lappage, M.G., Boatman, N.D., Crowe, A., Endalew, A.M., Potts, S.G., Somerwill, K.E., Biesmeijer, J.C., 2014. Climate-driven spatial mismatches between British orchards and their pollinators: increased risks of pollination deficits. Glob. Change Biol. 20, 2815-2828, http://dx.doi.org/10.1111/gcb.12577.

Radchuk, V., Johst, K., Groeneveld, J., Grimm, V., Schtickzelle, N., 2013. Behind the scenes of population viability modeling: predicting butterfly metapopulation dynamics under climate change. Ecol. Modell. 259, 62-73, http://dx.doi.org/10. 1016/j.ecolmodel.2013.03.014.

Refsgaard, J.C., van der Sluijs, J.P., Højberg, A.L., Vanrolleghem, P.A., 2007. Uncertainty in the environmental modelling process - a framework and guidance. Environ. Model. Softw. 22, 1543-1556, http://dx.doi.org/10.1016/j.envsoft.02.004.2007.

Ripa, J., Heino, M., 1999. Linear analysis solves two puzzles in population dynamics: the route to extinction and extinction in coloured environments. Ecol. Lett. 2 219-222, http://dx.doi.org/10.1046/j.1461-0248.1999.00073.x.

Root, T.L., Price, J.T., Hall, K.R., Schneider, S.H., Rosenzweig, C., Pounds, J.A., 2003. Fingerprints of global warming on wild animals and plants. Nature 421, 57-60.

Ruokolainen, L., Fowler, M.S., 2008. Community extinction patterns in coloured environments. Proc. R. Soc. B 275, 1775-1783, http://dx.doi.org/10.1098/rspb.2008. 0193. 
Saino, N., Ambrosini, R., Rubolini, D., von Hardenberg, J., Provenzale, A., Hüppop, K., Hüppop, O., Lehikoinen, A., Lehikoinen, E., Rainio, K., Romano, M., Sokolov, L., 2011. Climate warming, ecological mismatch at arrival and population decline in migratory birds. Proc. Biol. Sci. 278, 835-842, http://dx.doi.org/10.1098/rspb. 2010.1778.

Salguero-Gómez, R., Jones, O.R., Archer, C.R., Buckley, Y.M., Che-Castaldo, J., Caswell, H., Hodgson, D., Scheuerlein, A., Conde, D.A., Brinks, E., de Buhr, H., Farack, C. Gottschalk, F., Hartmann, A., Henning, A., Hoppe, G., Römer, G., Runge, J., Ruoff, T., Wille, J., Zeh, S., Davison, R., Vieregg, D., Baudisch, A., Altwegg, R., Colchero, F., Dong, M., de Kroon, H., Lebreton, J.-D., Metcalf, C.J.E., Neel, M.M., Parker, I.M., Takada, T., Valverde, T., Vélez-Espino, L.A., Wardle, G.M., Franco, M., Vaupel, J.W., 2015. The compadre Plant Matrix Database: an open online repository for plant demography. J. Ecol. 103, 202-218, http://dx.doi.org/10.1111/1365-2745. 12334

Saltelli, A., Chan, K., Scott, E.M., 2000. Sensitivity Analysis. Wiley, New York.

Sanders, D., van Veen, F.J.F., 2011. Ecosystem engineering and predation: the multitrophic impact of two ant species. J. Anim. Ecol. 80, 569-576, http://dx.doi.org/ 10.1111/j.1365-2656.2010.01796.x.

Scheller, R.M., Mladenoff, D.J., 2008. Simulated effects of climate change, fragmentation, and inter-specific competition on tree species migration in northern Wisconsin, USA. Clim. Res. 36, 191-202, http://dx.doi.org/10.3354/cr00745.

Schmolke, A., Thorbek, P., DeAngelis, D.L., Grimm, V., 2010. Ecological models supporting environmental decision making: a strategy for the future. Trends Ecol. Evol. 25, 479-486, http://dx.doi.org/10.1016/j.tree.2010.05.001.

Schurr, F.M., Pagel, J., Cabral, J.S., Groeneveld, J., Bykova, O., O'Hara, R.B., Hartig, F. Kissling, W.D., Linder, H.P., Midgley, G.F., Schröder, B., Singer, A., Zimmermann, N.E., 2012. How to understand species' niches and range dynamics: a demographic research agenda for biogeography. J. Biogeogr. 39, 2146-2162, http:// dx.doi.org/10.1111/j.1365-2699.2012.02737.x.

Schweiger, O., Settele, J., Kudrna, O., Klotz, S., Kühn, I., 2008. Climate change can cause spatial mismatch of trophically interacting species. Ecology 89, 3472-3479, http://dx.doi.org/10.1890/07-1748.1.

Singer, A., Kauhala, K., Holmala, K., Smith, G.C., 2009. Rabies in northeastern Europe - the threat from invasive raccoon dogs. J. Wildl. Dis. 45, 1121-1137, http://dx. doi.org/10.7589/0090-3558-45.4.1121.

Singer, A., Travis, J.M.J., Johst, K., 2013. Interspecific interactions affect species and community responses to climate shifts. Oikos 122, 358-366, http://dx.doi.org/ 10.1111/j.1600-0706.2012.20465.x.

Smith, G.C., Parrott, D., Robertson, P.A., 2008. Managing wildlife populations with uncertainty: cormorants Phalacrocorax carbo.J. Appl. Ecol.45, 1675-1682, http:// dx.doi.org/10.1111/j.1365-2664.2008.01380.x.

Snell, R.S., Huth, A., Nabel, J.E.M.S., Bocedi, G., Travis, J.M.J., Gravel, D., Bugmann, H., Gutiérrez, A.G., Hickler, T., Higgins, S.I., Reineking, B., Scherstjanoi, M., Zurbriggen, N., Lischke, H., 2014. Using dynamic vegetation models to simulate plant range shifts. Ecography 37, 1184-1197, http://dx.doi.org/10.1111/ecog.00580.

Spangenberg, J.H., Bondeau, A., Carter, T.R., Fronzek, S., Jaeger, J., Jylhä, K., Kühn, I. Omann, I., Paul, A., Reginster, I., Rounsevell, M., Schweiger, O., Stocker, A., Sykes, M.T., Settele, J., 2012. Scenarios for investigating risks to biodiversity. Glob. Ecol. Biogeogr. 21, 5-18, http://dx.doi.org/10.1111/j.1466-8238.2010.00620.x.

Stenseth, N., Durant, J., Fowler, M.S., Matthysen, E., Adriaensen, F., Jonzen, N., Chan, K., Liu, H., De Laet, J., Sheldon, B., Visser, M., Dhondt, A., 2015. Testing for effects of climate change on competitive relationships and coexistence between two bird species. Proc. R. Soc. B 282, 20141958, http://dx.doi.org/10.1098/rspb.2014. 1958.

Svenning, J.-C., Condit, R., 2008. Biodiversity in a warmer world. Science 322, 206-207, http://dx.doi.org/10.1126/science.1164542.

Svenning, J.-C., Gravel, D., Holt, R.D., Schurr, F.M., Thuiller, W., Münkemüller, T., Schiffers, K.H., Dullinger, S., Edwards, T.C., Hickler, T., Higgins, S.I., Nabel, J.E.M.S., Pagel, J., Normand, S., 2014. The influence of interspecific interactions on species range expansion rates. Ecography 37, 1-12, http://dx.doi.org/10.1111/j.16000587.2013.00574.x.

Swab, R.M., Regan, H.M., Matthies, D., Becker, U., Bruun, H.H., 2015. The role of demography, intra-species variation, and species distribution models in species' projections under climate change. Ecography 38, 221-230, http://dx.doi.org/10. 1111/ecog.00585.

Thébault, E., Fontaine, C., 2010. Stability of ecological communities and the architecture of mutualistic and trophic networks. Science 329, 853-856, http://dx.doi. org/10.1126/science.1188321.

Thomas, C.D., Bodsworth, E.J., Wilson, R.J., Simmons, A.D., Davies, Z.G., Musche, M., Conradt, L., 2001. Ecological and evolutionary processes at expanding range margins. Nature 411, 577-581, http://dx.doi.org/10.1038/35079066.
Thuiller, W., 2004. Patterns and uncertainties of species' range shifts under climate change. Glob. Change Biol. 10, 2020-2027, http://dx.doi.org/10.1111/j.13652486.2004.00859.x.

Thuiller, W., Araújo, M.B., Pearson, R.G., Whittaker, R.J., Brotons, L., Lavorel, S., 2004. Biodiversity conservation: uncertainty in predictions of extinction risk. Nature 430, http://dx.doi.org/10.1038/nature02716.

Thuiller, W., Münkemüller, T., Lavergne, S., Mouillot, D., Mouquet, N., Schiffers, K. Gravel, D., 2013. A road map for integrating eco-evolutionary processes into biodiversity models. Ecol. Lett. 16 (Suppl. 1), 94-105, http://dx.doi.org/10.1111/ ele.12104.

Topping, C.J., Alrøe, H.F., Farrell, K.N., Grimm, V., 2015. Per Aspera ad Astra: through complex population modeling to predictive theory. Am. Nat. 186, 669-674, http://dx.doi.org/10.1086/683181.

Travis, J.M.J., Brooker, R.W., Clark, E.J., Dytham, C., 2006. The distribution of positive and negative species interactions across environmental gradients on a duallattice model. J. Theor. Biol. 241, 896-902.

Travis, J.M.J., Münkemüller, T., Burton, O.J., Best, A., Dytham, C., Johst, K., 2007. Deleterious mutations can surf to high densities on the wave front of an expanding population. Mol. Biol. Evol. 24, 2334-2343, http://dx.doi.org/10.1093/molbev/ msm167.

Travis, J.M.J., Mustin, K., Benton, T.G., Dytham, C., 2009. Accelerating invasion rates result from the evolution of density-dependent dispersal. J. Theor. Biol. 259, $151-158$

Travis, J.M.J., Delgado, M., Bocedi, G., Baguette, M., Bartoń, K., Bonte, D., Boulangeat, I., Hodgson, J.A., Kubisch, A., Penteriani, V., Saastamoinen, M., Stevens, V.M., Bullock, J.M., 2013. Dispersal and species' responses to climate change. Oikos 122 , 1532-1540, http://dx.doi.org/10.1111/j.1600-0706.2013.00399.x.

Urban, M.C., 2015. Accelerating extinction risk from climate change. Science 348, 571-573, http://dx.doi.org/10.1126/science.aaa4984.

Václavík, T., Meentemeyer, R.K., 2012. Equilibrium or not? Modelling potential distribution of invasive species in different stages of invasion. Divers. Distrib. 18 73-83, http://dx.doi.org/10.1111/j.1472-4642.2011.00854.x.

Valladares, F., Matesanz, S., Araujo, M.B., Balaguer, L., Benito-Garzon, M., Cornwell W.K., Gianoli, E., Guilhaumon, F., van Kleunen, M., Naya, D., Nicotra, A.B., Poorter H., Zavala, M., 2014. The effects of phenotypic plasticity and local adaptation on forecasts of species range shifts under climate change. Ecol. Lett. 17, 1351-1364, http://dx.doi.org/10.1111/ele.12348.

Van der Vaart, E., Beaumont, M.A., Johnston, A.S.A., Sibly, R.M., 2015. Calibration and evaluation of individual-based models using Approximate Bayesian Computation. Ecol. Modell. 312, 182-190, http://dx.doi.org/10.1016/j.ecolmodel.2015. 05.020.

Van Nes, E.H., Scheffer, M., 2003. Alternative attractors may boost uncertainty and sensitivity in ecological models. Ecol. Modell. 159, 117-124, http://dx.doi.org/ 10.1016/S0304-3800(02)00278-8.

Violle, C., Jiang, L., 2009. Towards a trait-based quantification of species niche. J. Plant Ecol. 2, 87-93.

Voigt, W., Perner, J., Davis, A.J., Eggers, T., Schumacher, J., Bährmann, R., Fabian, B. Heinrich, W., Köhler, G., Lichter, D., Marstaller, R., Sander, F.W., 2003. Trophic levels are differentially sensitive to climate. Ecology 84, 2444-2453, http://dx. doi.org/10.1890/02-0266.

Walther, G.-R., 2010. Community and ecosystem responses to recent climate change. Philos. Trans. R. Soc. Lond. B: Biol. Sci. 365, 2019-2024, http://dx.doi.org/10. 1098/rstb.2010.0021.

Walther, G.R., Berger, S., Sykes, M.T., 2005. An ecological "footprint" of climate change. Proc. R. Soc. B: Biol. Sci. 272, 1427-1432.

Wiegand, T., Jeltsch, F., Hanski, I., Grimm, V., 2003. Using pattern-oriented modeling for revealing hidden information: a key for reconciling ecological theory and application. Oikos 100, 209-222.

Woodward, F.I., Williams, B.G., 1987. Climate and plant distribution at global and local scales. In: Prentice, I.C., van der Maarel, E. (Eds.), Theory and Models in Vegetation Science. Springer, Netherlands, pp. 189-197, http://dx.doi.org/10. 1007/978-94-009-4061-1.

Zarnetske, P.L., Skelly, D.K., Urban, M.C., 2012. Biotic multipliers of climate change. Science 336, 1516-1518, http://dx.doi.org/10.1126/science.1222732.

Zurell, D., Jeltsch, F., Dormann, C.F., Schröder, B., 2009. Static species distribution models in dynamically changing systems: how good can predictions really be? Ecography 32, 733-744, http://dx.doi.org/10.1111/j.1600-0587.2009.05810.x.

Zurell, D., Grimm, V., Rossmanith, E., Zbinden, N., Zimmermann, N.E., Schröder, B., 2012. Uncertainty in predictions of range dynamics: black grouse climbing the Swiss Alps. Ecography 35, 590-603, http://dx.doi.org/10.1111/j.1600-0587. 2011.07200.x. 